\title{
The Current Status of MOF and COF Applications
}

Ralph Freund, ${ }^{[\mathrm{a}]}$ Orysia Zaremba, ${ }^{[\mathrm{b}],[\mathrm{[c]}}$ Giel Arnauts, ${ }^{[\mathrm{d}]}$ Rob Ameloot, ${ }^{[\mathrm{d}]}$ Grigorii Skorupskii, ${ }^{[\mathrm{e}]}$ Mircea Dincă, ${ }^{[e]}$ Anastasiya Bavykina, ${ }^{\left[{ }^{[]}\right]}$Jorge Gascon, ${ }^{\left[{ }^{[]]}\right.}$Aleksander Ejsmont, ${ }^{[g]}$ Joanna Goscianska, ${ }^{[g]}$ Markus Kalmutzki, ${ }^{[\mathrm{h}]}$ Ulrich Lächelt, ${ }^{[i]}$ Evelyn Ploetz, ${ }^{[\mathrm{j}]}$ Christian S. Diercks, ${ }^{[\mathrm{k}],{ }^{*}}$ and Stefan Wuttke ${ }^{[\mathrm{c}],\left[\mathrm{[},{ }^{*}\right.}$

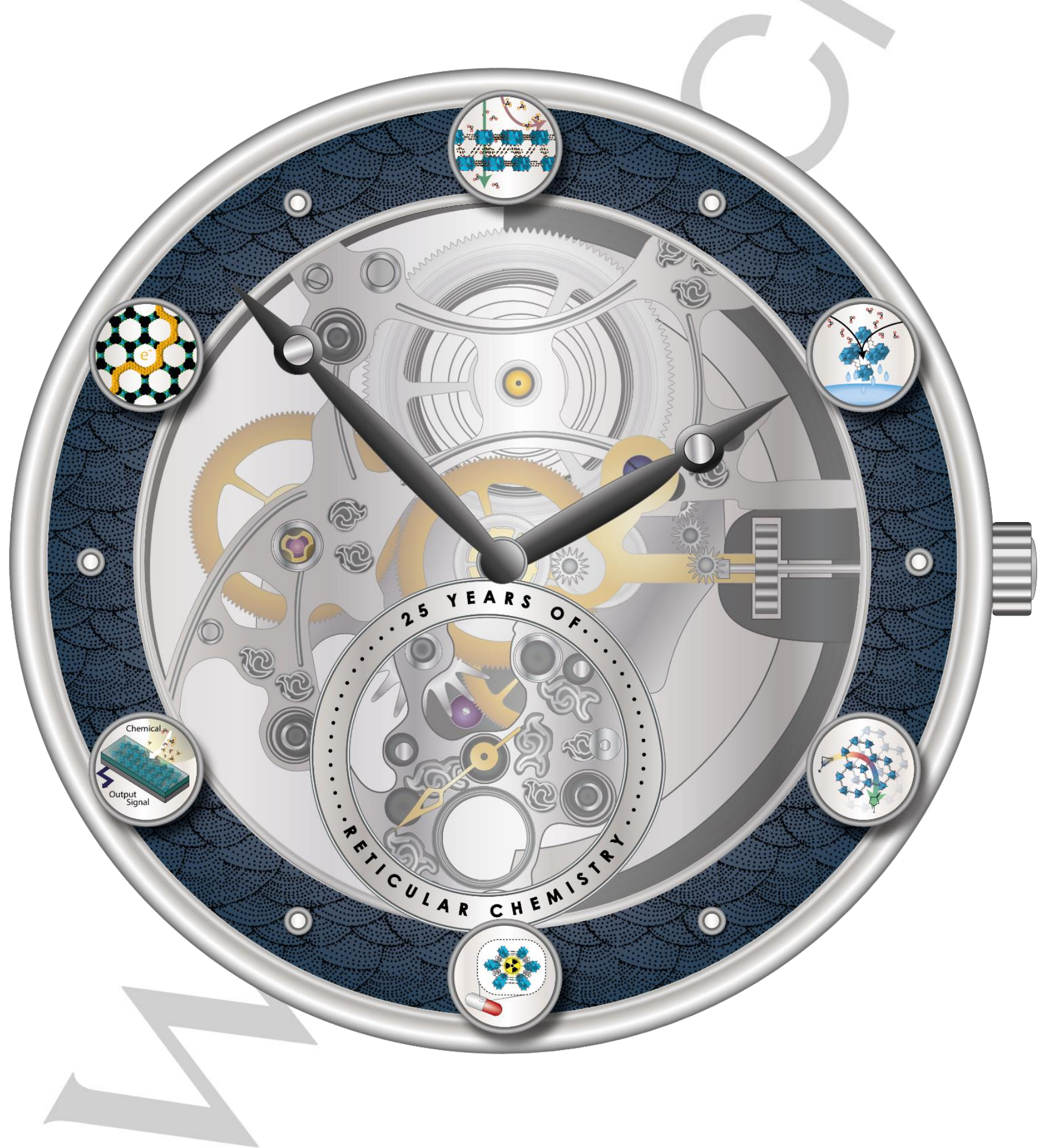


[a] Ralph Freund

Solid State Chemistry

University of Augsburg

86159 Augsburg, Germany

[b] Orysia Zaremba, Prof. Dr. Stefan Wuttke

BCMaterials

Basque Center for Materials

UPV/EHU Science Park, Leioa 48940, Spain

E-mail: stefan.wuttke@bcmaterials.net

[c] Orysia Zaremba

Department of Chemistry

University of California-Berkeley

Berkeley, CA, 94720 USA

[d] Giel Arnauts, Prof. Dr. Rob Ameloot

Center for Membrane Separations, Adsorption, Catalysis and Spectroscopy (cMACS)

KU Leuven, B-3001 Leuven, Belgium

[e] Grigorii Skorupskii, Prof. Dr. Mircea Dincă

Department of Chemistry

Massachusetts Institute of Technology

Cambridge, MA 02139, USA

[f] Dr. Anastasiya Bavykina, Prof. Dr. Jorge Gascon

King Abdullah University of Science and Technology

KAUST Catalysis Center (KCC), Advanced Catalytic Materials

23955-6900, Saudi Arabia

[g] Aleksander Ejsmont, Prof. Dr. Joanna Goscianska

Faculty of Chemistry

Adam Mickiewicz University in Poznan

61-614 Poznan, Poland

[h] Dr. Markus J. Kalmutzki

Anton Paar Germany GmbH

73760 Ostfildern

[i] Dr. Ulrich Lächelt,

Department of Pharmacy and Center for NanoScience (CeNS),

LMU Munich

81377 Munich, Germany

[j] Dr. Evelyn Ploetz

Department of Chemistry and Center for NanoScience (CeNS)

LMU Munich

81377 Munich, Germany

[k] Dr. Christian S. Diercks,

Materials Sciences Division

Lawrence Berkeley National Laboratory, Kavli Energy NanoSciences Institute

Berkeley, CA, 94720 USA

E-mail: cdiercks@scripps.edu

[l] Prof. Dr. Stefan Wuttke

IKERBASQUE

Basque Foundation for Science

48009 Bilbao, Spain

Abstract: The amalgamation of different disciplines is at the heart of reticular chemistry and has broadened the boundaries of chemistry by opening up an infinite space of chemical composition, structure, and material properties. Reticular design has enabled the precise prediction of crystalline framework structures, tunability of chemical composition, incorporation of various functionalities onto the framework backbone, and as a consequence, fine-tuning of metalorganic framework (MOF) and covalent organic framework (COF) properties beyond that of any other material class. Leveraging the unique properties of reticular materials has resulted in significant advances from both a fundamental and an applied perspective. Here, we wish to review the milestones in MOF and COF research and give a critical view on progress in their real-world applications. Finally, we briefly discuss the major challenges in the field that need to be addressed to pave the way for industrial applications.

\section{Introduction}

Reticular chemistry has provided scientists with fundamentally novel tools of material design, providing a rational approach for the design of a myriad of metal-organic framework (MOF) and covalent organic framework (COF) structures. The key concept of reticular design lies in the linking of organic and inorganic molecular building units through strong directional chemical bonds to yield stable crystalline extended structures. A notable consequence of this approach is the ability to control the pore size of MOFs and COFs by variation of the length of their employed organic linkers without altering the framework's underlying topology. The past decades have witnessed vast opportunities of reticular design culminating in a broad array of MOF $(>100000)^{[1]}$ and COF $(>570)^{[1]}$ structures that exhibit unique properties. ${ }^{[1,2]}$

Hallmark features of reticular materials that sparked the attention of the scientific community can be broadly categorized into six points (Figure 1): (I) Precise control over structures types by consideration of preferred topologies based on the connectivity and shape of the molecular building blocks; (II) exceptional porosity and tunable pore size; (III) post-synthetic modification 
(PSM) as a tool for chemical optimization of the pore interior for optimized interaction with guest species; (IV) multivariate (MTV) structures with multiple metals and/or organic linkers enabling the creation of heterogeneity within order within the pores; (V) facile characterization by $\mathrm{X}$-ray diffraction due to the periodic arrangement of constituents (crystals); and (VI) straightforward scalable synthesis. The unique combination of these aspects has contributed to the extensive study of reticular materials and their properties (Table 1).

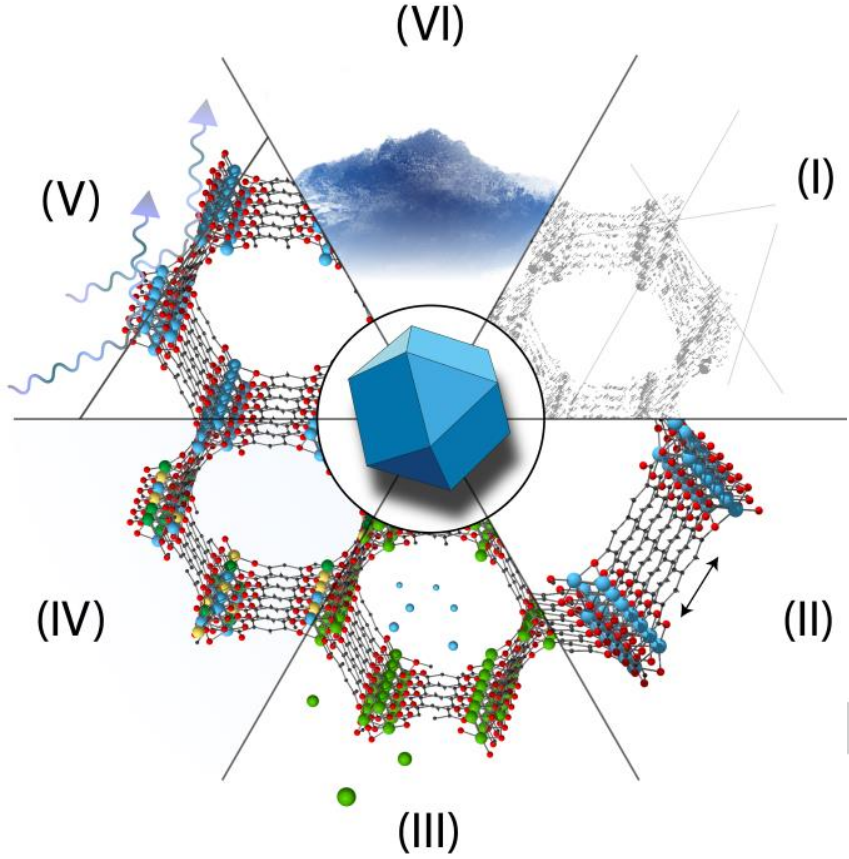

Figure 1. Hallmark features of MOFs and COFs: (I) blueprint; (II) tunable porosity; (III) post-synthetic modification to alter framework-guest interactions, (IV) multivariate functionalization; (V) facile characterization; and (VI) scalable synthesis.

The field of reticular chemistry has been developing at an extraordinary pace,$^{[2]}$ greatly exceeding the scope of other porous materials. The high level of control over the materials' functionality and prediction of its properties based on the reticular design principles are the core concepts that have led to this extensive promotion. From the outset of this development, it has been envisioned that the core concept of controlling pore chemistry would ultimately result in breakthrough performance of MOFs and COFs in diverse fields of application and eventually commercialization.

To boost real-world applications, a number of issues have to be addressed. One of the essential issues is the development of large-scale green synthesis protocols. Many start-up companies have undertaken efforts to pilot-scale MOF production for use in diverse applications. ${ }^{[3]}$ Today, it is possible to synthesize MOF powders at low-cost (below $20 €^{-1}$ ) on a ton-scale, and with high space-time-yield (STY; $\left.10000 \mathrm{~kg} \mathrm{~m}^{-3} \mathrm{~d}^{-1}\right) \cdot{ }^{[4]}$ The main determinant of the cost in MOF production is the price of the organic linker (5$100 € \mathrm{~kg}^{-1}$ ), as well as material loss in STY following the activation process. ${ }^{[4]}$

Processability is a major point that is often overlooked in MOF and COF research. This problem arises due to the powdered crystalline nature of reticular materials that often preclude their practical application in unprocessed form. ${ }^{[5]}$ Additionally, it is also important to expand the investigation of the long-term, ambient, and chemical stabilities of reticular materials to ensure their robust and reliable performance. Further industrial requirements include the need for green synthesis conditions ${ }^{[3]}$ : (I) low temperatures and pressures; (II) non-hazardous, inexpensive, renewable, recyclable, and non-corrosive precursors such as hydroxides or oxides; (III) non-toxic, non-flammable solvents, ideally water; (IV) cost-effective energy sources, etc. Finally, MOF synthesis and activation protocols are usually not optimized, thus, an important branch of research is focused on developing efficient protocols for MOF large-scale production..$^{[4,6]}$ Meanwhile, the COF field is still in its infancy, and there is a large space left for fundamental exploration, as well as up-scaling and optimization of their production.

At present, over 27 companies are working on pilot-scaling MOF synthesis and their commercialization (Figure 2). One of the first achievements was the development of vehicles equipped with MOF-based natural gas storage systems. Following this successful prototype, the first commercial product TruPick based on a MOF adsorbent that stores and releases 1-methylcyclopropene to ripen fruit and vegetables was released to the market.. ${ }^{[7]}$ Another commercial product designed soon thereafter was the ION-X gas storage and delivery system for hazardous gases used in the electronics industry (such as arsine, phosphine, and boron trifluoride). ${ }^{[7]}$ Apart from significant advances in gas storage applications, accomplishments in medicine have been demonstrated, as well. Specifically, the phase I clinical trial of a RiMO-301 radio-immunotherapy against advanced tumors in human patients has successfully been initiated as the first-MOF-in-human clinical study. ${ }^{[8]}$ Finally, the application of MOF based devices has revolutionized the area of water harvesting due to their superiority over alternative materials in arid climate. ${ }^{[9]}$

Overall, this review will focus on the impressive progress in harnessing the unique MOF and COF properties in various fields of application such as gas separation and storage, vapor adsorption, catalysis, chemical sensing, biomedical applications, and ionic conductors. We wish to spotlight the large application potential of those reticular materials by presenting the milestones that have propelled the research done in this field into novel and unexpected realms of material chemistry. 


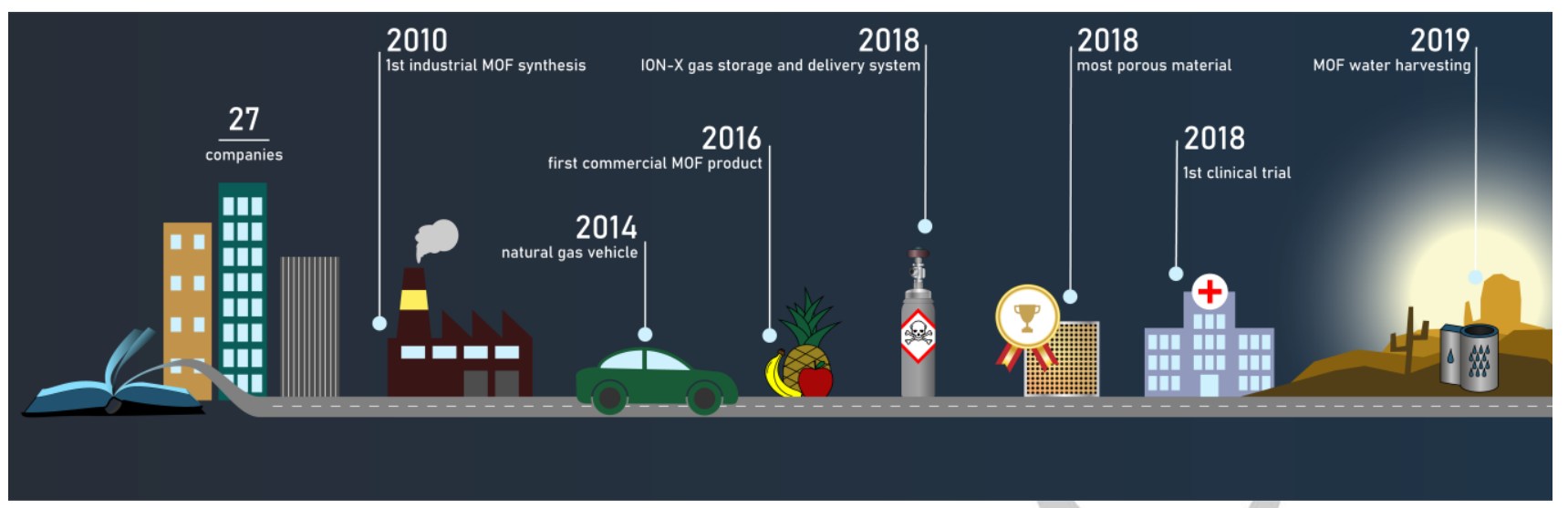

Figure 2. The pathway of MOF commercialization: from book knowledge to technologies.

Table 1. Comparison of the typical material properties of MOFs and COFs.

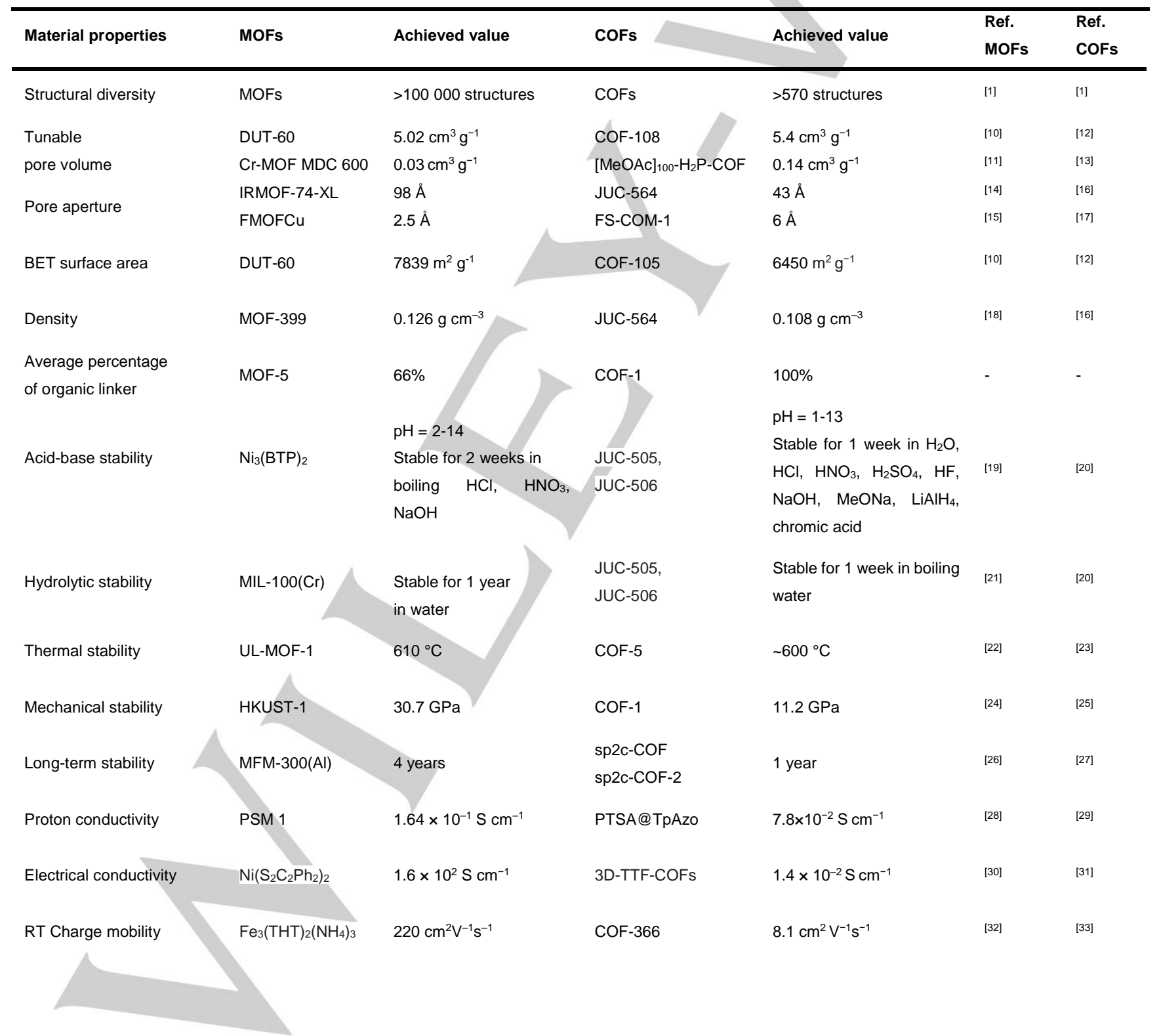


WILEY-VCH REVIEW - Accepted Article

\begin{tabular}{|c|c|c|c|c|c|c|}
\hline Photoconductivity & MIL-177-HT & $4 \times 10^{-4} \mathrm{~cm}^{2} \mathrm{~V}^{-1} \mathrm{~s}^{-1}$ & $\mathrm{NiPc} \mathrm{COF}$ & $1.3 \mathrm{~cm}^{2} \mathrm{~V}^{-1} \mathrm{~s}^{-1}$ & [34] & [35] \\
\hline $\mathrm{CO}_{2}$ uptake & MOF-210 & $\begin{array}{l}2400 \mathrm{mg} \mathrm{g}^{-1} \\
(298 \mathrm{~K}, 50 \text { bar })\end{array}$ & COF-102 & $\begin{array}{l}1180 \mathrm{mg} \mathrm{g}^{-1} \\
(298 \mathrm{~K}, 35 \text { bar })\end{array}$ & [36] & [37] \\
\hline $\mathrm{CH}_{4}$ uptake & HKUST-1 & $\begin{array}{l}1770 \mathrm{mg} \mathrm{g}^{-1} \\
(298 \mathrm{~K}, 40 \text { bar })\end{array}$ & COF-102 & $\begin{array}{l}187 \mathrm{mg} \mathrm{g}^{-1} \\
(298 \mathrm{~K}, 35 \text { bar })\end{array}$ & & [37] \\
\hline $\mathrm{H}_{2}$ uptake & NU-1501-M & $\begin{array}{l}14 \text { wt } \% \\
\text { (swing } 77 \mathrm{~K} / 100 \rightarrow 160 \\
\mathrm{~K} / 5 \text { bar) }\end{array}$ & COF-102 & $\begin{array}{l}7.24 \text { wt. } \% \\
\text { (77 K, } 40 \text { bar) }\end{array}$ & [39] & [37] \\
\hline $\mathrm{H}_{2} \mathrm{O}$ uptake & MOF-303 & $\begin{array}{l}480 \mathrm{mg} \mathrm{g}^{-1} \\
\left(P / P_{0}=0.15\right)\end{array}$ & COF-432 & $\begin{array}{l}300 \mathrm{mg} \mathrm{g}^{-1} \\
\left(P / P_{0}=0.3\right)\end{array}$ & & [41] \\
\hline
\end{tabular}

\section{Gas Storage and Separation}

The deficiency of fossil fuels, combined with pressing environmental issues and climate change caused by rapid industrialization and modern civilization, has spurred scientists to seek alternative cleaner fuels. ${ }^{[42]}$ In comparison to solid coal and liquid petroleum, gaseous fuels (e.g., hydrogen, methane) are more environmentally friendly given their lower carbon emissions and higher thermal efficiency. ${ }^{[37]}$ Nowadays, the main challenge for gaseous fuels lies in their transportation, storage, and conversion. These usually require harsh operating conditions and a high energy cost. Developing porous materials for gas storage systems based on adsorption under moderate conditions offers a promising alternative. ${ }^{[43]}$ Compared to other materials, MOFs and
COFs stand out due to their high porosity, chemically adjustable pore dimension, and stability. ${ }^{[44,45]}$ Changing framework composition, and thus porosity, is the first approach to selectively adsorb one type of gas molecules from a mixture. However, gaseous molecules tend to be very similar in shape and size. Thus, other requirements for MOFs are necessary to enhance the affinity for a specific adsorbate (e.g., ligand modification). Metallic nodes can have a significant impact on the adsorption selectivity towards different gases. For instance, fabrication of frameworks with imperfect crystal structures where open metal sites (OMS) are present can induce a framework's specificity to a particular type of gas molecules. ${ }^{[46]}$ Overall, by taking advantage of all the above-mentioned features, significant progress has been made in this field, which will be reviewed in this chapter (Figure 3, Table S1).

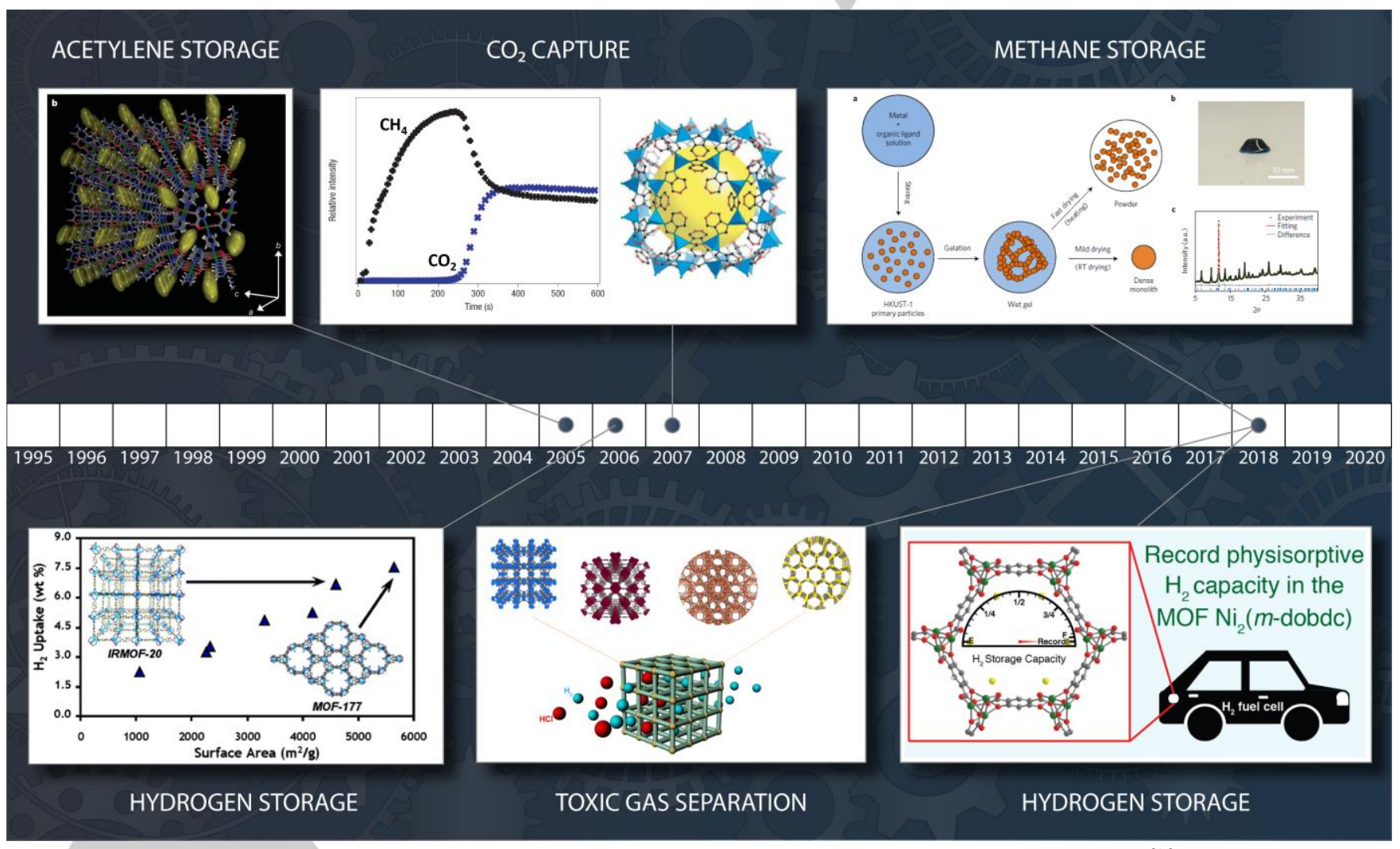

Figure 3. Illustrative timeline of the milestones in gas storage and separation: Acetylene storage (Reprinted with permission from ref. ${ }^{[47]}$. Copyright 2005 Nature) Hydrogen storage (Reprinted with permission from ref. ${ }^{[48]}$. Copyright 2006 American Chemical Society). $\mathrm{CO}_{2}$ capture (Reprinted with permission from ref. ${ }^{[49]}$. Copyright 2007 Nature). Methane storage (Reprinted with permission from ref. ${ }^{[38]}$. Copyright 2018 Nature). Toxic gas separation (Reprinted with permission from ref. ${ }^{[50]}$. Copyright 2018 American Chemical Society). Hydrogen storage (Reprinted with permission from ref. ${ }^{[51]}$. Copyright 2018 American Chemical Society). 


\subsection{Hydrogen Storage}

Hydrogen is considered an excellent alternative energy source for a variety of fuel cell applications. Therefore, much effort has been devoted to its storage. The large surface area and tunable structure of MOFs can provide strong adsorption sites for $\mathrm{H}_{2}$. $^{[43,52]}$ $\mathrm{H}_{2}$ adsorption is achieved at cryogenic temperature $(77 \mathrm{~K})$. The energy of interaction between hydrogen and adsorbent surfaces is low. MOF materials therefore need to have a pore size, which is similar in diameter to that of a hydrogen molecule $(2.89 \AA)$ to enhance this interaction. ${ }^{[53,54]}$ Moreover, gravimetric hydrogen uptake at high pressure grows with increasing pore volume and surface area of MOFs. This phenomenon was especially observed for $\mathrm{Cu}_{3}(\mathrm{BTC})_{2}$ (BTC = benzene-1,3,5-tricarboxylic acid) prepared via mechanochemical synthesis. ${ }^{[55]}$ Hydrogen uptake of IRMOF-1, -6, -11, and -20, MOF-177, MOF-74, and HKUST-1 at $77 \mathrm{~K}$ also strongly correlate with the surface area. ${ }^{[48]}$ One of the highest hydrogen uptake capacities of $7.5 \mathrm{wt} \%$ was achieved at $77 \mathrm{~K}$ and 70 bar using MOF-177 that consists of tetrahedral $\left[\mathrm{Zn}_{4} \mathrm{O}\right]^{6+}$ clusters linked by the tritopic linker BTB (1,3,5benzenetribenzoate). The $\mathrm{H}_{2}$ adsorption in the MOF is dominated by weak van-der-Waals interactions with a low heat of adsorption. MOF-177 also shows a decent $\mathrm{H}_{2}$ sorption capacity ( $\left.0.62 \mathrm{wt} \%\right)$ at room temperature. ${ }^{[56]}$

In $\mathrm{H}_{2}$ storage, the presence of unsaturated metal sites with low coordination number plays a crucial role and increases the gas uptake. For instance, it was reported that four-coordinated OMS in $\mathrm{Mn}_{2}$ (dsbdc) composed of $\mathrm{Mn}^{2+}$ and 2,5-disulfido-1,4benzenedicarboxylate ( $\mathrm{dsbdc}^{4-}$ ) are found to be beneficial for enhancing adsorption capacity towards hydrogen. Although the $\mathrm{H}_{2}$ uptake (1.6 wt\% at $77 \mathrm{~K}$ and 1.2 bar) by $\mathrm{Mn}_{2}$ (dsbdc) was not a record one, the presented strategy was further developed. ${ }^{[57]}$ The MOFs $\mathrm{M}_{2}$ ( $m$-dobdc) ( $\mathrm{M}=\mathrm{Co}, \mathrm{Ni}$; $m$-dobdc ${ }^{4-}=4,6$-dioxido-1,3benzenedicarboxylate) and their isomeric counterparts $M_{2}$ (dobdc) having OMS are promising adsorbents for $\mathrm{H}_{2}$ at near-ambient temperatures. It was found that $\mathrm{Ni}_{2}(m$-dobdc) exhibits the highest volumetric capacity of $11.0 \mathrm{~g} \mathrm{~L}^{-1}$ in the pressure range of 5-100 bar and $298 \mathrm{~K}$, and $23.0 \mathrm{~g} \mathrm{~L}^{-1}$ using temperature swing between $198-298 \mathrm{~K}$. Its high $\mathrm{H}_{2}$ uptake is associated with highly polarizing $\mathrm{Ni}^{2+}$ adsorption sites causing large binding enthalpies and dense packing of $\mathrm{H}_{2}$ within the material. ${ }^{[51]}$ Interestingly, the sodalite-type MOF

$\left[\mathrm{Mn}(\mathrm{DMF})_{6}\right]_{3}\left[\left(\mathrm{Mn}_{4} \mathrm{Cl}\right)_{3}(\mathrm{BTT})_{8}\left(\mathrm{H}_{2} \mathrm{O}\right)_{12}\right]_{2} \cdot 42 \mathrm{DMF} \cdot 11 \mathrm{H}_{2} \mathrm{O} \cdot 20 \mathrm{CH}_{3} \mathrm{OH}$ can be partially desolvated, which yields a material with exceptional total $\mathrm{H}_{2}$ uptake $(6.9 \mathrm{wt} \%, 70 \mathrm{~K}, 90$ bar) and a record high isosteric heat of adsorption of $10.1 \mathrm{~kJ} \mathrm{~mol}^{-1}$. This is directly attributed to $\mathrm{H}_{2}$ binding at coordinatively unsaturated $\mathrm{Mn}^{2+}$ centers within the framework. ${ }^{[58]}$ The replacement of $\mathrm{Mn}^{2+}$ with $\mathrm{Cu}^{2+}$ in a sodalite-type MOF can further enhance the density of exposed coordination sites for strong $\mathrm{H}_{2}$ binding. ${ }^{[59]}$ Such strong binding of $\mathrm{H}_{2}$ can also be increased in MOFs and COFs by e.g. Li-doping. ${ }^{[60-}$ 62]

The efficient storage of $\mathrm{H}_{2}$ can be achieved via separation from a mixture of gases. For instance, high separating factors for COFs' membranes were observed: 31.4 for $\mathrm{H}_{2} / \mathrm{CO}_{2}$ (NUS$2 @ P B I){ }^{[63]}, 139.7$ for $\mathrm{H}_{2} / \mathrm{CH}_{4}$ (TpBD@PBI-Bul), ${ }^{[64]}$ and 84 for $\mathrm{H}_{2} / \mathrm{N}_{2}$ (COF-LZU1-ACOF-1). ${ }^{[65,66]}$

\subsection{Methane Storage}

Natural gas, comprised primarily of methane, is an energy source with the potential to replace vehicular liquid hydrocarbon fuel. A long-standing challenge in the field is to develop highly porous adsorbents that can efficiently and safely store natural gas at ambient temperature and moderate pressure. ${ }^{[43,53]}$ Following pioneering work using the solvothermally crystallized 3D framework $\left[\mathrm{Co}_{2}\left(4,4^{\prime}-\mathrm{bpy}\right)_{3}\left(\mathrm{NO}_{3}\right)_{4}\right]$ for methane adsorption, ${ }^{[67]}$ the subject has been intensively explored. Detailed studies have shown that electrostatic and van-der-Waals interactions between MOFs and $\mathrm{CH}_{4}$, as well as framework flexibility have a major impact on their volumetric methane delivery and uptake capacities. ${ }^{[43]}$

The electrostatic interplay between MOFs and $\mathrm{CH}_{4}$ takes place at OMS in frameworks. Therefore, materials with high densities of OMS such as - M-MOF-74 ( $\mathrm{M}=\mathrm{Mg}, \mathrm{Mn}, \mathrm{Co}, \mathrm{Ni}, \mathrm{Zn}$ ) exhibit high $\mathrm{CH}_{4}$ sorption capacities. ${ }^{[68]}$ Among them Ni-MOF-74 stands out for its extraordinarily high total volumetric methane uptake (230 $\mathrm{cm}^{3} \mathrm{~cm}^{-3}, 35$ bar, $298 \mathrm{~K}$ ). This is related to the high polarizing ability of nickel ions and the resultant electrostatic interaction between $\mathrm{OMS}$ and $\mathrm{CH}_{4}$ molecules. ${ }^{68]}$

The strength of van-der-Waals interaction between $\mathrm{CH}_{4}$ and frameworks can be modulated through the rational design of pore size and shape of MOFs, as reported for Al-soc-MOF-1, ${ }^{[69]}$ HKUST-1, ${ }^{[70]}$ PCN-250 $\left(\mathrm{Fe}_{2} \mathrm{Co}\right)^{[71]}$, and UTSA-76a. ${ }^{[72]}$ Al-socMOF-1 is composed of trigonal prismatic $\mathrm{Al}_{3} \mathrm{O}(\mathrm{OOC})_{6}$ clusters and tetratopic TCPT linkers $\left(\mathrm{H}_{4}\right.$ TCPT $=3,3$ ",5,5"-tetrakis(4carboxyphenyl)-p-terphenyl) and features an impressive total methane uptake $\left(0.42 \mathrm{~g} \mathrm{~g}^{-1}, 65 \mathrm{bar}\right)$ and working capacity $(0.37 \mathrm{~g}$ $\mathrm{g}^{-1}, 5-65 \mathrm{bar}$ ) at $298 \mathrm{~K}$ attributed to weak host-guest interaction occurring on the surfaces. ${ }^{[69]}$ For HKUST-1, PCN-250 $\left(\mathrm{Fe}_{2} \mathrm{Co}\right)$, and UTSA-76a, most methane adsorption sites are located at window sites, corners of large cages and centers of small cages at high pressure. ${ }^{[71,73]}$ The monolithic framework monoHKUST-1 exhibits an outstanding methane capacity of $259 \mathrm{~cm}^{3} \mathrm{~cm}^{-3}$ at 65 bar after successful densification and shaping, rendering it the first adsorbent to achieve the volumetric target of the US Department of Energy for methane storage systems. ${ }^{[38]}$

Another way to achieve a high volumetric methane deliverable capacity is to use flexible MOFs that exhibit methane isotherms with a steep step in $\mathrm{CH}_{4}$ release before the pressure decreases to 5 bar. Two isostructural MOFs, $\mathrm{Co}(\mathrm{bdp})$ and $\mathrm{Fe}(\mathrm{bdp})\left(\mathrm{H}_{2} \mathrm{bdp}=\right.$ 1,4-benzenedi(4'-pyrazole)), possess such a feature. The channels of both MOFs can switch between a 'collapsed' and an 'expanded' state in response to changes in $\mathrm{CH}_{4}$ pressure. $\mathrm{Co}(\mathrm{bdp})$ shows one of the highest deliverable capacities for methane $\left(197 \mathrm{~cm}^{3} \mathrm{~cm}^{-3}, 5-65\right.$ bar, $298 \mathrm{~K}$ ), although its total $\mathrm{CH}_{4}$ uptake is much lower than that of many other reported MOFs. ${ }^{[74]}$

\subsection{Acetylene Storage}

Acetylene plays an important role in modern industry as one of the starting compounds in the production of fine chemicals and electronic materials. ${ }^{[52,53]}$ However, it cannot be stored under high pressure due to its explosive nature. The earliest example of a MOF used in acetylene storage is $\mathrm{Cu}_{2}(\mathrm{pzdc})_{2}(\mathrm{pyz}) \quad($ pzdc $=$ pyrazine-2,3-dicarboxylate; pyz = pyrazine). The material showed a high adsorption affinity $\left(42.5 \mathrm{~kJ} \mathrm{~mol}^{-1}\right)$ to $\mathrm{C}_{2} \mathrm{H}_{2}$ molecules, which were hydrogen-bonded to the uncoordinated carboxylate oxygen atoms on the pore surface. ${ }^{[4]}$ Later, six porous coordinationpolymers with the general formula of $\left[M_{2} L_{2}(\text { dabco })\right]_{n}(M=C u / Z n$, 
$\mathrm{L}=$ bdc, ndc, and adc) were employed in acetylene adsorption Here, changing the bridging dicarboxylate ligands and inorganic metal ions enabled the facile modulation of their pore sizes, surface, and sorptive properties. The highest $\mathrm{C}_{2} \mathrm{H}_{2}$ uptakecapacity of $106 \mathrm{~cm}^{3} \mathrm{~g}^{-1}$ at $298 \mathrm{~K}$ and 1.01 bar was observed for $\mathrm{Zn}_{2}$ (ndc) $)_{2}$ (dabco). ${ }^{[75]}$ Systematical evaluation of acetylene adsorption properties of MOFs with different pore structures, including those containing OMS (HKUST-1, MOF-505), with small pores (MOF-508, MIL-53), and large pores (MOF-5, ZIF-8) established that large pores are not favorable for $\mathrm{C}_{2} \mathrm{H}_{2}$ storage, while small pores allow for uptake of a moderate amount of gas. Notably, HKUST-1 and MOF-505 exhibited the highest gravimetric acetylene uptake-capacity of $201 \mathrm{~cm}^{3} \mathrm{~g}^{-1}$ and 148 $\mathrm{cm}^{3} \mathrm{~g}^{-1}$, respectively, underlining the importance of OMS in acetylene storage. ${ }^{[76]}$ CoMOF-74, which also possesses a high concentration of OMS, also shows a high volumetric acetylene uptake-capacity of $230 \mathrm{~cm}^{3} \mathrm{~g}^{-1}$ at ambient conditions. This is still the record value for volumetric acetylene storage in MOFs. ${ }^{[7]}$ Recently, an extraordinarily high gravimetric acetylene uptake $\left(244 \mathrm{~cm}^{3} \mathrm{~g}^{-1}\right)$ was reported for the NbO-type copper-based MOF ZJU-12 constructed from 5,5'-(2,6-dimethoxy naphthalene-1,5diyl)diisophthalic acid. At $298 \mathrm{~K}$ and 1.01 bar, it features the highest gravimetric $\mathrm{C}_{2} \mathrm{H}_{2}$ capacity among all MOFs applied so far in acetylene storage. ${ }^{[78]}$

\section{4. $\mathrm{CO}_{2}$ Capture and Separation}

Some materials exhibit excellent uptake towards several gases, e.g. COF-JLU2 for $\mathrm{CO}_{2}\left(217 \mathrm{mg} \mathrm{g}^{-1}\right), \mathrm{CH}_{4}\left(38 \mathrm{mg} \mathrm{g}^{-1}\right)$, at 1 bar and $273 \mathrm{~K}$, and $\mathrm{H}_{2}\left(16 \mathrm{mg} \mathrm{g}^{-1}\right)$ at $77 \mathrm{~K}^{.79]}$ However, it is preferable to design material with an affinity towards just one type of gas. Thus, selective and efficient $\mathrm{CO}_{2}$ capture has been a major objective for many years. Considerable research efforts have been devoted to designing MOFs and COFs as adsorbents for $\mathrm{CO}_{2}$ capture.

Amongst a series of MOFs, such as IRMOF-1, MOF-177, catenated IRMOF-11, MOF-2, MOF-74, amine-functionalized IRMOF-3, alkyl-functionalized IRMOF-6, OMS-decorated MOF505 and HKUST-1, MOF-177 exhibited the highest $\mathrm{CO}_{2}$ uptake $\left(33.5 \mathrm{mmol} \mathrm{g}^{-1}\right.$ at room temperature and $\left.35 \mathrm{bar}\right){ }^{[80]}$ Later on, $\mathrm{Mg}$ MOF-74 was found to also show a high $\mathrm{CO}_{2}$ adsorption capacity of $380 \mathrm{mg} \mathrm{g}^{-1}$ but at a much lower pressure (below 1 bar). ${ }^{[81]}$ This high capacity was obtained after solvent removal and creating space in the pore structure. Moreover, the desolvation of MOF induced and generated OMS, which have a good affinity to $\mathrm{CO}_{2}$ at low pressures. ${ }^{[82]} \mathrm{OMS}$ are mainly responsible for $\mathrm{CO}_{2}$ uptake, and hence changing inorganic building blocks (IBUs) can crucially alter adsorption. For $\mathrm{M}_{3}(\mathrm{BTC})_{2}$ in which metals, such as $\mathrm{Cu}, \mathrm{Cr}$, $\mathrm{Ni}, \mathrm{Zn}, \mathrm{Mo}, \mathrm{Ru}$ can create nodes, Ru-based MOF showed the highest heat of adsorption compared $\left(32.6 \mathrm{~kJ} \mathrm{~mol}^{-1} ; 11 \mathrm{wt} \% \mathrm{CO}_{2}\right.$ uptake-capacity at 1 bar). ${ }^{[83]}$ Partially exchanging one type of metal with another can also enhance the material performance. Partially replacing $\mathrm{Zr}$ with $\mathrm{Ti}$ in $\mathrm{UiO}-66$ resulted in a pore size decrease and a larger isosteric heat of $\mathrm{CO}_{2}$ adsorption, which finally led to an increased capacity from 2.3 to $4.0 \mathrm{mmol} \mathrm{g}^{-1}$.84] Another strategy to decrease pore dimensions and increase the surface area of MOFs in favor of $\mathrm{CO}_{2}$ adsorption is catenation. Catenated CuTATB-60 (TATB $=4,4^{\prime}, 4^{\prime \prime}$-s-triazine-2,4,6triyltribenzoate) displayed better $\mathrm{CO}_{2}$ sorption capacity $(189 \mathrm{mg}$ $\mathrm{g}^{-1}$ ) compared to unmodified CuTATB-30 (156 mg g $\left.{ }^{-1}\right) \cdot{ }^{[85]}$ Poresize modulation for series of different ultra-microporous pillared
SIFSIX-3-M (SiF"-; M = Cu, Ni, Zn) MOFs has also yielded remarkable $\mathrm{CO}_{2}$ sorbents. SIFSIX-3-Cu adsorbs the highest amount of $\mathrm{CO}_{2}\left(1.24 \mathrm{mmol} \mathrm{g}^{-1}\right)$ under atmospheric conditions. ${ }^{[86]}$ Even higher $\mathrm{CO}_{2}$ uptake of $7.29 \mathrm{mmol} \mathrm{g}^{-1}$ was again obtained for the pillared MOF TMU-42 $\left.\left\{\left[\mathrm{Zn}_{2} \text { (fum) }\right)_{2}(4-b p d b)\right] \cdot 2 \mathrm{H}_{2} \mathrm{O}\right\}_{\mathrm{n}}$ (fum = fumarate; 4-bpdb = 1,4-bis(4-pyridyl)-3,4-diaza-1,3-butadiene) owing to its flexible nature and breathing phenomena, reaching a heat adsorption of $30.6 \mathrm{~kJ} \mathrm{mmol}^{-1}$ at a gate-opening pressure. ${ }^{[87]}$ Further studies revealed that chemical modifications of MOFs with hydroxyl, ${ }^{[88]}$ sulfonic ${ }^{[89]}$ and amine groups can improve $\mathrm{CO}_{2}$ sorption abilities significantly, as was reported for Mg-MOF-74. ${ }^{90]}$ Other MOF functionalization strategies have also been considered to enhance $\mathrm{CO}_{2}$ capture. Internal hybridization (in the case of MTV-MOF-5-EHI) enables the increase of the $\mathrm{CO}_{2} / \mathrm{CO}$ adsorption efficiency by about $400 \%$ compared to its counterpart MOF-5. ${ }^{[91]}$

At early stages, ZIFs (e.g., ZIF-20) were applied for separation of $\mathrm{CO}_{2} / \mathrm{CH}_{4}{ }^{\left[{ }^{[92]}\right.}$ Further reports proved that a composite fabrication could additionally improve adsorption selectivity towards $\mathrm{CO}_{2}$. ZIF-8 creating IL/MOF (IL = ionic liquid) with 1-(2-hydroxyethyl)3-methylimidazolium dicyanamide indicated 45 and 5.7 times higher $\mathrm{CO}_{2} / \mathrm{CH}_{4}$ and $\mathrm{CO}_{2}$ uptake, respectively, compared to single ZIF-8. ${ }^{[93]}$

\subsection{Toxic Gas Separation}

Selective adsorption of toxic gases produced in many industrial processes requires the use of highly separative porous materials, such as MOFs and COFs. It was established that easily polarized $\mathrm{CO}_{2}$ can more readily be captured than toxic $\mathrm{CO}$ from binary mixtures by, e.g., TIFSIX-2-Cu-I. ${ }^{\left[{ }^{94]}\right.}$ Specifically good separation abilities and interaction with $\mathrm{CO}$ was observed for the material $\mathrm{Fe}_{2} \mathrm{Cl}_{2}$ (bbta) $\left(\mathrm{H}_{2}\right.$ bbta $=1 H, 5 H$-benzo(1,2-d:4,5-d')bistriazole). ${ }^{[95]}$ It was capable of separating $\mathrm{CO}$ from $\mathrm{CO} / \mathrm{N}_{2}$ and $\mathrm{CO} / \mathrm{H}_{2}$ mixtures. The iron(II) OMS revealed high affinity to $\mathrm{CO}$ with a peculiar adsorbate-induced electronic response.

In turn, the paddle-wheel MFM-170 containing $\mathrm{Cu}^{2+} \mathrm{OMS}$ showed good $\mathrm{SO}_{2}$ selectivity over $\mathrm{CO}_{2}$ and $\mathrm{NO}_{2}$ along with a high $\mathrm{SO}_{2}$ sorption capacity of $17.5 \mathrm{mmol} \mathrm{g}^{-1}$ under ambient conditions. ${ }^{[96]}$

NOTT-300 can also be utilized as an efficient adsorbent of $\mathrm{SO}_{2}$ from binary mixtures with $\mathrm{CH}_{4}, \mathrm{~N}_{2}$ and $\mathrm{H}_{2}$, indicating separation factors of $3.62,6.52$ and $>10^{5}$, respectively. Interestingly, hydrogen bonds between $\mathrm{SO}_{2}$ and the MOF's hydroxyl groups are reinforced via interactions with protons of the framework's aromatic rings. ${ }^{[97]}$

Another case of reversible capture of toxic gases is $\mathrm{H}_{2} \mathrm{~S}$ adsorption by MIL-53(AI)-TDC (TDC = 2,5thiophenedicarboxylate). ${ }^{[98]}$ From a mixture of 5 vol\% $\mathrm{H}_{2} \mathrm{~S}$ and 9 vol\% $\mathrm{N}_{2}$, the material selectively adsorbs $\mathrm{H}_{2} \mathrm{~S}$, exhibiting the highest $\mathrm{H}_{2} \mathrm{~S}$ uptake-capacity of $18.13 \mathrm{mmol} \mathrm{g}^{-1}$ at $303 \mathrm{~K}$ and 1 bar thus far.

The separation of $\mathrm{HCl} / \mathrm{H}_{2}$ to receive clean hydrogen fuel is challenging. Cr-based MIL-101 overcame this hurdle. It exhibits an unprecedented separating factor of 1363 towards gaseous HCl. ${ }^{[99]}$ The application of this material resulted in $>99.997 \%$ purity of hydrogen.

The approach with additional adsorbate conversion was applied for $\mathrm{NO}_{2}$ separation from $\mathrm{CO}_{2}$ and $\mathrm{SO}_{2}$ mixtures by MFM520. ${ }^{[100]}$ Bowtie-shaped pores of the framework could confine uncommonly stable dimer $\mathrm{N}_{2} \mathrm{O}_{4}$ (4.2 $\mathrm{mmol} \mathrm{g}^{-1}, 0.01$ bar). Owing 
to the 24-fold weak, additive supramolecular interactions, $\mathrm{NO}_{2} @ M F M-520$ fully released $\mathrm{NO}_{2}$ in water and formed $\mathrm{HNO}_{3}$.

A great example of MOFs outperforming commercial benchmark adsorbents in the process of air purification from $\mathrm{NH}_{3}$ is $\mathrm{UiO}-66-\mathrm{COOH} .{ }^{[50]}$ Breakthrough studies revealed its high selectivity towards $\mathrm{NH}_{3}$ over $\mathrm{N}_{2}$ under dry and humid conditions and an extraordinary $\mathrm{NH}_{3}$ adsorption capacity of $55 \mathrm{mg} \mathrm{g}^{-1}$ due to the high concentration of hydroxyl groups at the MOF surface. Among porous materials, COF-10 exhibited exceptional $\mathrm{NH}_{3}$ uptake of $15 \mathrm{~mol} \mathrm{~kg}^{-1}$ at $298 \mathrm{~K}$ and 1 bar, due to the strong Lewis acid-base interactions. Furthermore, complete $\mathrm{NH}_{3}$ desorption was achieved under vacuum at $473 \mathrm{~K}$, with reusability for several cycles. ${ }^{[101]}$

In the context of real commercial application of MOFs in toxic gas separation and sub-atmospheric storage, the most notable milestone is the material ION-X. ${ }^{[102]}$ It is a granular two MOFbased product that increases purity and safe storage of arsine, boron trifluoride, and phosphine, which are gases used in the semiconductor industry.

\section{Vapor Sorption}

Porous materials find wide-spread application in sorptionbased processes, however, their use in water sorption driven applications is limited. This is in large parts because most vapor sorption-driven processes such as adsorption-driven heat pumps (ADHPs) and chillers (ADCs) have a lower coefficient of performance (COP) than their mechanical counterpart when classical desiccants are employed. Nonetheless, in the face of societal challenges, such as increasing energy consumption for heating or cooling of residential areas and water scarcity, progressing these technologies has attracted more interest over the past decades. Early reports of MOFs and COFs gave a glimpse at the potential of these materials with respect to the development of energy-efficient water sorption driven devices. This section will focus on the key developments in reticular chemistry that propelled reticular framework materials from unstable laboratory curiosities to materials facilitating the realization of efficient ADHPs and ADCs, and adsorption-based atmospheric water harvesting (AWH) (Figure 4).

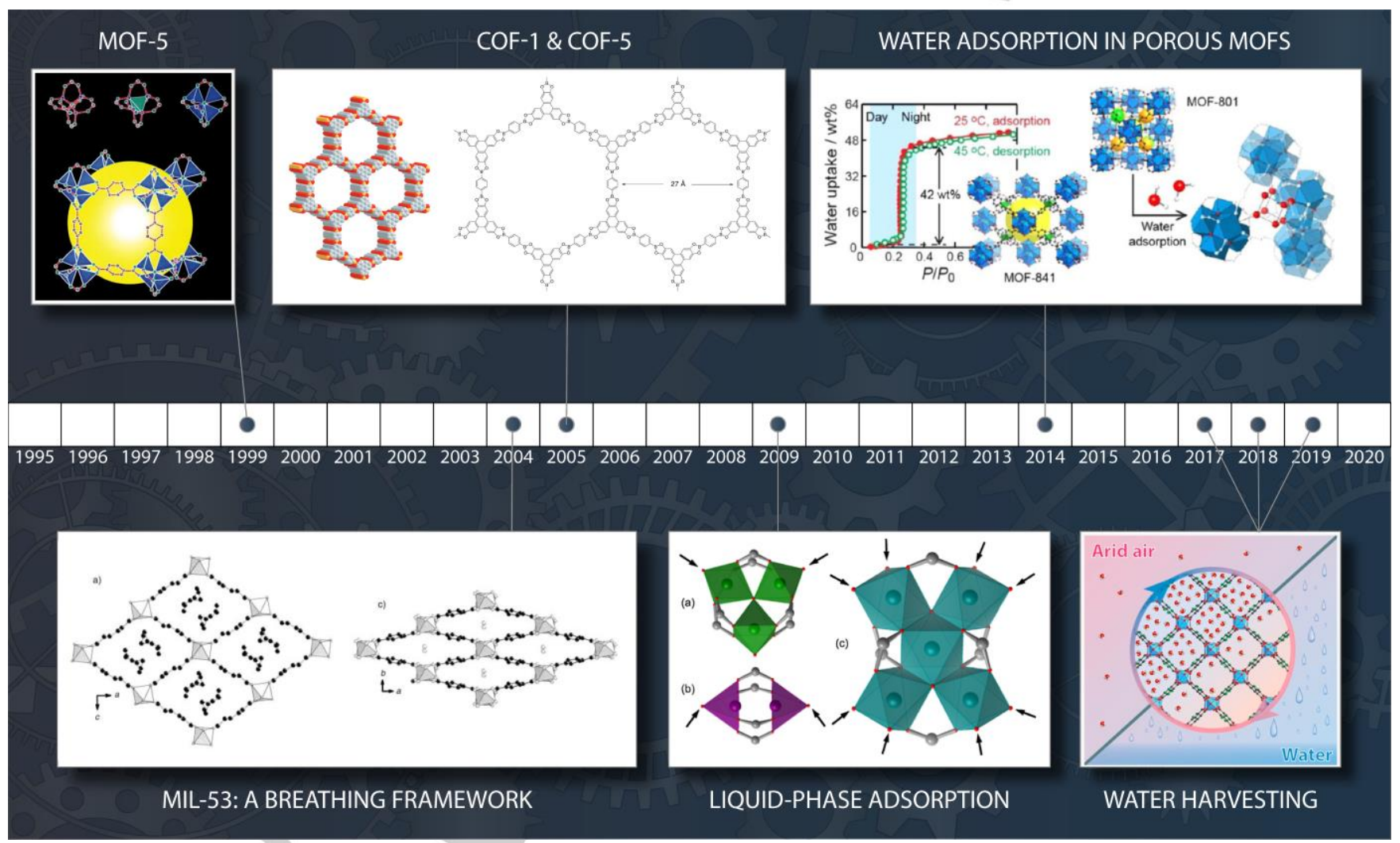

Figure 4. Illustrative timeline of the milestones in the vapor adsorption field: MOF-5 (Reprinted with permission from ref. ${ }^{[103]}$. Copyright 1999 Springer Nature). MIL53: a breathing framework (Reprinted with permission from ref. ${ }^{[104]}$. Copyright 2004 Wiley - VCH). COF-1 and COF-5 capture (Reprinted with permission from ref. ${ }^{[23]}$ Copyright 2005 The American Association for the Advancement of Science). Liquid-phase adsorption (Reprinted with permission from ref. ${ }^{[105]}$. Copyright 2011 Springer Nature). Water adsorption in porous MOFs (Reprinted with permission from ref. ${ }^{[106]}$. Copyright 2014 American Chemical Society). Water harvesting (Reprinted with permission from ref. ${ }^{[40]}$. Copyright 2019 American Chemical Society).

\subsection{Hydrolytic stability}

Aside from the hydrolytic instability of these $1^{\text {st }}$ generation MOFs, water vapor sorption was a rather unusual method at this time. Thus, it was not until the report more than five years later about the first water-stable MOFs constructed from secondary building units (SBUs) of highly charged metals, that the watersorption behavior of MOFs gained the interest of researchers. ${ }^{[105]}$

The long time it took to realize the synthesis of MOFs based on $\mathrm{Al}^{3+}$ (e.g., MIL-53), $\mathrm{Cr}^{3+}$ (e.g., MIL-100 and MIL-101), and $\mathrm{Zr}^{4+}$ SBUs (e.g., UiO-66) is explained by the synthetic challenges that had to be overcome. ${ }^{[104,107]}$ When compared to $1^{\text {st }}$ generation MOFs, the stronger metal-linker bonds in $\mathrm{Al}-, \mathrm{Cr}-$, and $\mathrm{Zr}-\mathrm{MOFs}$ 
require dramatically different reaction conditions to facilitate the reversibility necessary for the formation of crystalline products. While $1^{\text {st }}$ generation MOFs were synthesized from a mixture of metal salt and linker in DMF by liberation of the base upon heating this yield amorphous powders for $\mathrm{Al}^{3+}, \mathrm{Cr}^{3+}$ and $\mathrm{Zr}^{4+}$ due to fast and uncontrolled precipitation. A key point for the successful synthesis was the usage of strong acidic modulators rendering the reticulation process reversible. The chemistry of Al-, Cr- and $\mathrm{Zr-MOFs}$ expanded rapidly after the first reports, giving rise to a large number of structurally diverse MOFs. ${ }^{[108]}$ These MOFs proved to possess the architectural, mechanical, and chemical stability required to support permanent porosity and impart hydrolytic stability. ${ }^{[109]}$

At the same time, another class of reticular framework materials (i.e., COFs) emerged. COF-1 and COF-5 marked the first report of crystalline, extended structures consisting of only covalent bonds. ${ }^{[23]}$ Even though the boronic ester bonds connecting the building units of these COFs were highly unstable towards water, the prospect of covalent extended solids hinted at their potential in vapor sorption driven applications. Similarly, how MOF chemistry evolved over the past decade, the chemistry of COFs was developed in the coming year with respect to their linkages and topologies. ${ }^{[110]}$

\subsection{Sorption behavior}

With hydrolytically stable MOFs being accessible studies of their water sorption behavior ga ined interest. While early reports mostly highlighted the instability of $1^{\text {st }}$ generation MOFs, they also outlined the potential of more stable MOFs. ${ }^{[105]}$ Additionally, the first explanations for the unique sorption-behavior of MOFs were proposed; the heterogeneous surface of MOFs composed of hydrophilic (the SBUs) and hydrophobic (the linkers) regions results in a so-called 'bridging effect'. ${ }^{[11]}$ This means that adsorption is initiated on the polar primary sorption sites resulting in pore filling via 'bridging' of hydrophobic regions. The consequent S-shaped isotherms and comparatively low isosteric heats of adsorption $\left(q_{\mathrm{st}}\right)$ are in strong contrast to the sorptionbehavior of classical desiccants like zeolites. These findings sparked interest in studying MOFs for their applicability in water sorption driven processes.

In the following years, in-depth studies of the water sorptionbehavior of MOFs revealed their superiority over classical desiccants in lower energy (i.e., temperature) processes, such as ADHPs and ADCs. ${ }^{[12,113]}$ Reports of water sorption isotherms of different MOFs helped to establish correlations between pore size surface chemistry, and the shape of the sorption isotherm. ${ }^{[14,115]}$ An ideal isotherm shape was delineated and used for the selection of promising MOFs, such as $\mathrm{CAU}-10 \mathrm{H}$, Al-fumarate, MIL-101, and MIL-100, which were shown to have great potential for ADHPs and ADCs. ${ }^{[16]}$ In this context, their hydrolytic stability was further supported by unchanged sorption capacities after hundreds of adsorption-desorption cycles. Besides the development of new MOFs, methods for shaping and coating these materials were investigated and large prototypes built using these newly developed methods. ${ }^{[117]}$

\subsection{MOF water harvesting}

Intense research on the synthesis of hydrolytically stable MOFs resulted in hundreds of new compounds. Among them, MOF-801, which was argued to be capable of capturing water from the atmosphere at a low relative humidity $(\mathrm{RH})$ and releasing it with minimal energy input due to its unique sorption behavior. ${ }^{[106]}$ In this work, the water sorption mechanism in MOF-801 was elucidated using diffraction techniques confirming the 'bridgingeffect' proposed earlier; the presence of primary adsorption sites affords adsorption of water molecules at low $\mathrm{RH}$, which then act as secondary sorption sites facilitating spontaneous pore filling at slightly higher $\mathrm{RH}$ as indicated by a steep uptake in the sorption isotherm. Practical proof for the feasibility of an $\mathrm{AWH}$ - producing clean water from the air - using MOF-801 was reported only two years later. ${ }^{[18]}$ This report sparked great interest in the development of novel materials for this technology and in a relatively short period of time new promising candidates were reported. ${ }^{[14]}$ New concepts like the use of linkers that form more hydrolytically stable metal-linker bonds were explored culminating in the report of $\mathrm{Co}_{2} \mathrm{Cl}_{2}(\mathrm{BTDD})$, which marked a new record for the maximum sorption capacity at that time $\left(0.97 \mathrm{~g} \mathrm{~g}^{-1}\right) .{ }^{[119]}$ While the cylindrical pores of $\mathrm{CO}_{2} \mathrm{Cl}_{2}$ (BTDD) in its dehydrated form have a diameter larger than the critical diameter $D_{\mathrm{C}}$ for condensation, no hysteresis is observed because the pore diameter is decreased below $D_{\mathrm{C}}$ by adsorption of water on the open-metal sites of the $\mathrm{SBU}$ at very low $\mathrm{RH}$. This allows for reversible pore filling and a large maximum capacity while maintaining the low inflection point $\left(P / P_{0}=0.29\right)$ required for $\mathrm{AWH}$. In this context, MOF-303 marks another key development. ${ }^{[120]}$ Combining a rod-like aluminum SBU with a short polar linker, effects an S-shaped isotherm with a maximum uptake of $0.48 \mathrm{~g} \mathrm{~g}^{-1}$ and an inflection point at $P / P_{0}=$ 0.15 , thus allowing the capture of water at very low $\mathrm{RH}$ (e.g., desert air). MOF-303 was demonstrated to capture $0.175 \mathrm{~L}_{\text {water }}$ $\mathrm{kg}_{\text {MOF }}{ }^{-1}$ day ${ }^{-1}$ from desert air in a passive device. In a later report, the production of $0.7 \mathrm{~L}_{\text {water }} \mathrm{kg}_{\mathrm{MOF}^{-1}}$ day $^{-1}$ in an active device was reported. ${ }^{[40]}$ Kinetics measurements described in this work indicated that diffusion limitations mainly originate from the packing of the MOF material and less from the shape and connectivity of the actual pore system. With up to $8.66 \mathrm{~L}_{\text {water }}$ $\mathrm{kg}^{-1}$ MOF day ${ }^{-1} \mathrm{Zr}-\mathrm{MOF}-808$ was reported to achieve the highest productivity up-to-date. ${ }^{[121]}$ However, with an inflection point at $P / P_{0}=0.36$, MOF-808 is not suitable for use in arid regions. Additionally, the reported productivity was calculated from the adsorption/desorption isotherms and does not take the losses experienced in an actual AWH device into account.

\subsection{COF water harvesting}

Very recently, COF-432 - the first COF suitable for the application in an $\mathrm{AWH}$ - was reported. ${ }^{[41]}$ Its ultra-high hydrolytic stability in combination with a maximum capacity of $0.3 \mathrm{~g} \mathrm{~g}^{-1}$ and an inflection point at $P / P_{0}=0.3$ makes it a promising candidate for $\mathrm{AWH}$ in less arid regions. Improvements in the chemical stability of reticular framework materials have fostered research aiming for their application in water sorption driven processes. This research led to a deeper understanding of structure-property relations and the development of design principles for purpose-made adsorbents. Considering this rapid development, reticular chemistry will continue to reveal its undeniable potential with respect to tailored adsorbents for sorption-driven applications. 


\section{Catalysis}

The importance of catalysis cannot be overstated. Catalysts and humanity have a long history together, from ancient civilizations producing alcoholic beverages to modern days consumer goods manufacturing and ecological problem solving.

The eminent virtues of MOFs - chemical tunability, large and accessible surface area, and bespoke pore architecture - have prompted considerable research. Over the last years, the number of publications appearing on this topic has kept growing over the past decade proving MOFs' potential in the field (Figure 5, Table S2).

MOFs are commonly employed as heterogeneous catalysts in the form of pristine solids or post-synthetically modified ones. The most straightforward approach is to use their metal nodes if open coordination sites are available. Organic linkers can be utilized as catalytic sites, too. In addition to intrinsic catalytic activity, MOFs are widely used as hosts for encapsulation of additional catalytic sites, e.g., metal nanoparticles or enzymes, due to their tunable pore design. When some MOFs undergo a controlled thermal decomposition, they act as precursors, allowing a one-step synthesis of highly loaded, well-distributed supported nanoparticle-based catalysts. On top of that, not only thermal catalysis but also electro- and photo-chemistry are possible when utilizing these materials. ${ }^{[122]}$

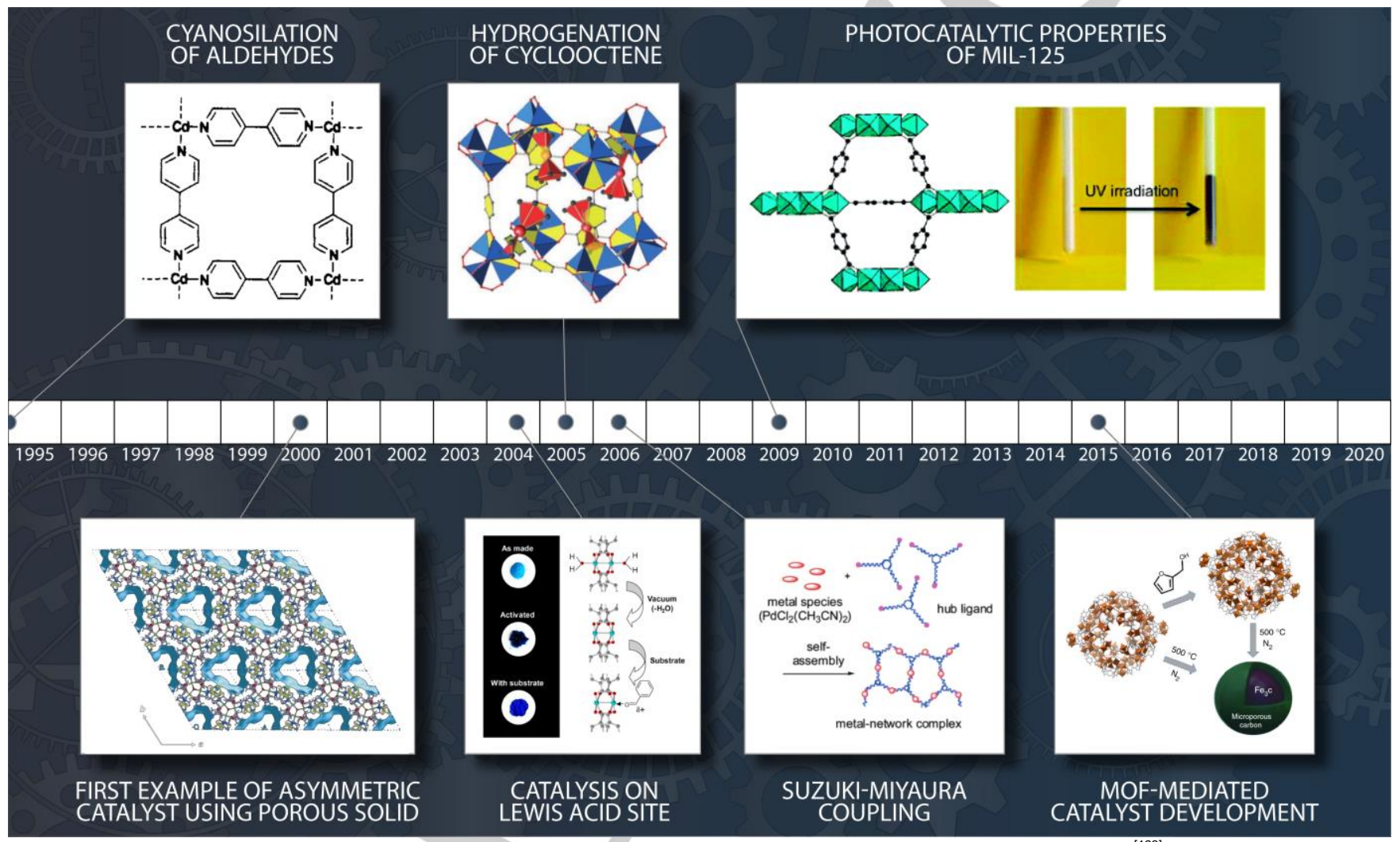

Figure 5. Illustrative timeline of the milestones in the catalysis field: Cyanosilation of aldehydes (Reprinted with permission from ref. ${ }^{[23]}$. Copyright 1994 American Chemical Society). First example of asymmetric catalysis using porous solid (Reprinted with permission from ref. ${ }^{[128]}$. Copyright 2000 Springer Nature). Catalysis on Lewis acid site (Reprinted with permission from ref. ${ }^{[129]}$. Copyright 2004 Elsevier Inc.). Hydrogenation of cyclooctene (Reprinted with permission from ref. ${ }^{[130]}$ Copyright 2005 Wiley - VCH). Suzuki-Miyaura coupling (Reprinted with permission from ref. ${ }^{[131]}$. Copyright 2006 American Chemical Society). Photocatalytic properties of MIL-125 (Reprinted with permission from ref. ${ }^{[132]}$. Copyright 2009 American Chemical Society). MOF-mediated catalyst development (Reprinted with permission from ref. ${ }^{[133]}$. Copyright 2015 Springer Nature).

\subsection{Early reports, catalytically active MOFs}

The earliest reports on the catalytic activity of coordination polymers date back to the 90 s. First, a $2 \mathrm{D}$ network $\left[\mathrm{Cd}\left(\mathrm{NO}_{3}\right)_{2}(4,4-\right.$ bipy ${ }_{2}$ ] was employed for the cyanosilylation of aldehydes. ${ }^{[123]}$ The heterogeneity of the catalyst was proven since neither the cadmium salt nor the bipyridine linker alone were able to catalyze the reaction. Moreover, the dependency of yield on the substrate size was established, manifesting the importance of the MOF's pore size and highlighting the prospect of shape selectivity. A 3D coordination-polymer based on $\mathrm{Ru}(\mathrm{II})$ and 1,4-diisocyanobenzene ligands was found to be active in hexene hydrogenation. The partial breakage of the $\mathrm{Ru}-\mathrm{Ru}$ stacking interaction turned the framework into an active, heterogeneous catalyst. ${ }^{[124]}$ Another early example are so-called host-networks based on $\mathrm{Ti}, \mathrm{Zr}$ or $\mathrm{Al}$. These networks were found to incorporate and readily desorb several guest molecules, as well as catalyze Diels-Alder reactions of these guests. ${ }^{[125,126]}$

Indium based MOFs are one of the early examples of using coordination polymers in catalysis. Four metal-organic frameworks $\quad \operatorname{In}(\mathrm{BDC})_{1.5}$ (bipy), $\quad \ln _{2}(\mathrm{OH})_{2}(\mathrm{BDC})_{2}$ (phen $)_{2}$, $\ln (\mathrm{BTC})\left(\mathrm{H}_{2} \mathrm{O}\right)$ (bipy) and $\ln (\mathrm{BTC})\left(\mathrm{H}_{2} \mathrm{O}\right)$ (phen) were synthesized and tested as catalysts for aldehyde acetalization. Three out of four showed high activity with a yield of up to $70 \%$. The first framework was not active due to the indium center hindrance toward the reactants. ${ }^{[127]}$ 


\subsection{Impact of Frameworks Stability}

The catalytic properties of $\mathrm{MOF} \mathrm{Cu}_{3}(\mathrm{BTC})_{2}$, were first used in the cyanosilylation of benzaldehyde. Water removal revealed the framework's mild Lewis acidity and promoted substrate activation. At the same time, the instability of this MOF required the careful choice of reaction conditions. ${ }^{[129]}$

In general, the application of MOFs in the field of catalysis has not been a smooth ride despite their high metal content. Their use is hampered by thermal and chemical stability, moisture sensitivity, or blockage of the metals by the organic linkers. Nevertheless, the progress in the field has advanced tremendously.

A MOF based on Pt/Gd and 2,2'-bipyridine-5,5'-dicarboxylate (BDPC), in which the Pt environment mimics that of well-known homogeneous catalysts, was found to be stable up to $350^{\circ} \mathrm{C}$. $\mathrm{Pt}$ centers are coordinated to $\mathrm{Cl}^{-}$and the $\mathrm{N}$-atoms of the BPDC showed catalytic activity toward $\mathrm{C}-\mathrm{H}$ bond cleavage of hydrocarbons upon water solvent removal. ${ }^{[134]}$ Similar work was reported for the $\mathrm{Pt} / \mathrm{Y}$ system, which showed further improvement and stabilty up to $400{ }^{\circ} \mathrm{C}$. ${ }^{[135]}$

The first $\mathrm{Pd}$-based, catalytically active coordination polymer was a network prepared via self-assembly from $\mathrm{PdCl}_{2}\left(\mathrm{CH}_{3} \mathrm{CN}\right)_{2}$ and a trisphosphine hub with three flexible alkyl-chain linkers. This network complex efficiently catalyzed the Suzuki-Miyaura reaction under atmospheric conditions in water, while showing stable catalytic activity. ${ }^{[131]}$

\subsection{Lewis Acid Catalysis}

The discovery of Lewis acidity in $\mathrm{Cu}_{3}(\mathrm{BTC})_{2}$ inspired many fields in catalytic research. The synthesis of this MOF has been optimized. Its structure, as well as the nature of its catalytic site, was studied thoroughly. $\mathrm{Cu}_{3}(\mathrm{BTC})_{2}$ got identified as a highly selective Lewis acid catalyst for terpene derivative isomerization. Next, the focus shifted to catalyst's reusability. Though the selectivity remained constant over several reaction cycles, the reaction rate decreased with each run. Here, crystal fragmentation and deposit formation within the pores were identified as the root causes. However, washing the sample in ethanol, water or a mixture was found to regenerate its activity. ${ }^{[136]}$ To date, $\mathrm{Cu}_{3}(\mathrm{BTC})_{2}$ has successfully been employed as a catalyst in a vast number of reactions, including coupling reactions, $\mathrm{CO}_{2}$ fixation, and Friedel-Crafts reaction to name a few. ${ }^{[122]}$

Unsaturated metal centers do not only act as active sites themselves but also offer further functionalization. For instance, in Cr-based MIL-101, electron-rich functional groups ethylenediamine and diethylenetriamine were grafted on the unsaturated $\mathrm{Cr}$ (III) sites. Such catalysts showed higher conversion in the Knoevenagel condensation of benzaldehyde and ethyl cyanoacetate than the pristine MIL-101 or similarly grafted SBA-15. ${ }^{[137]}$ The challenge in this application of MOFs resides in increasing Lewis acidity strength.

\subsection{Enantiselective Catalysis}

The first asymmetric catalysis, which employed an ordered porous material was achieved via the inclusion of an enantiopure ligand into a tri-nuclear zinc-based 2D-network. The resulting solid contained chiral 1D channels.

An enantiomeric excess of $8 \%$ was achieved for a transesterification reaction. Though this number does not look impressive, this was the first reported asymmetric induction in a coordination polymer. ${ }^{[128]}$ Later, chiral porous zirconium phosphonates containing Ru-BINAP ${ }^{[138]}$ and Ru-BINAP-1,2diphenylethylenediamine ${ }^{[139]}$ moieties were employed as enantioselective catalysts for the hydrogenation of $\beta$-keto esters and aromatic ketones. Today, enantiomeric excess values have already reached $99.2 \%$. A framework, constructed by linking infinite 1D $\left[\mathrm{Cd}(\mu-\mathrm{Cl})_{2}\right]_{n}$ zigzag chains with chiral bipyridine bridging ligands containing orthogonal secondary functional groups, was successfully used as an asymmetric catalyst for the addition of diethylzinc to aromatic aldehydes to afford chiral secondary alcohols at up to $93 \%$ enantiomeric excess. ${ }^{[140]}$

\subsection{Catalytic multi-metal MOFs}

The diverse chemistry of MOFs does not limit one's creativity. Thus, the field of catalysis has benefited from the discovery of bimetallic MOFs. One of the earliest examples is the bimetallic $\mathrm{Zr}$ (Ti)-NDC-MOF (NDC = 2,6-naphthalen-dicarboxylate) with $\mathrm{Ti}(\mathrm{IV})$ ions introduced into the preformed Zr-NDC framework. The resulting materials were decent Lewis acid catalysts for cascade reactions involving the Meerwein-Ponndorf-Verley reduction followed by etherification, reactions of cyclization of citronellal, and isomerization of $\alpha$-pinene oxide. ${ }^{[141]}$ Currently, bimetallic MOFs can be designed with the desired ratio between metals. MIL-100 (Fe'"I, Ni") MOFs containing different proportions of $\mathrm{Ni}(\mathrm{II})$ were synthesized and studied as heterogeneous catalysts. With the adjustment of the metal reactivity, $\mathrm{Ni}^{\prime \prime}$ cation was permitted into the framework. The mixed-metal MIL-100(Fe, Ni) catalyzed the Prins reaction between $\beta$-pinene and paraformaldehyde; an improvement of the catalytic activity of more than one order of magnitude has been determined in the case of the catalyst containing $5 \% \mathrm{Ni}$ compared to the pure Fe framework. ${ }^{[142]}$

\subsection{Ligand Design}

Not only different metals but also various organic ligands can be incorporated into MOFs to design catalysts. A series of metallated UiO derivatives with a wide range of catalytic applications were synthesized. Here, 2-phenylpyridyl or bipyridyl ligands were employed, where some of them were metallated with Ir, Re or Ru complexes. These functional ligands allowed using these UiO-67-like frameworks as heterogeneous catalysts in water oxidation, $\mathrm{CO}_{2}$ reduction, and organic photocatalysis. ${ }^{[143]}$

\subsection{Enzyme Mimics}

The chemical tunability of MOFs allows for accurate with a target transformation in mind. For instance, the iron dimer active site of the enzyme methane monooxygenase, which capable of converting methane into methanol, was mimicked in a MOF. The aluminum-based MIL-53 was post-synthetically modified electrochemically; isolated Fe dimers were incorporated into the framework, allowing it to perform this challenging transformation within a heterogeneous catalyst. ${ }^{[144]}$

\subsection{Nanoparticle Catalysis in MOFs}

Due to their high porosity, MOFs can serve as suitable hosts for nanoparticles. MOF-5 was found to absorb metal-organic chemical vapor deposition precursors. These incorporated 
compounds were reduced to yield the corresponding metal nanoparticles. The obtained solids were tested for methanol production and cyclooctene hydrogenation. ${ }^{[130]}$ A similar approach was used to load the same MOF with Ru nanoparticles. Gas-phase loading with the volatile compound $[R u(\operatorname{cod})(\cot )]$ (cod $=1,5$-cyclooctadiene, $\cot =1,3,5$-cyclooctatriene) was followed by hydrogenolysis of the adsorbed complex inside the porous structure of MOF-5. The obtained Ru@MOF-5 catalyst was successfully used in benzyl alcohol oxidation and benzene hydrogenation. ${ }^{[145]}$ Chromium-based MIL-101 was also soon established as a remarkably stable support for nanoparticles, i.e., palladium in hydrogenation reactions, with significantly higher activity than palladium on activated carbon. ${ }^{[146]}$ Currently, the amount of research dedicated to nanoparticle encapsulation in MOFs is large and keeps on growing. ${ }^{[122]}$

\subsection{Immobilization of catalytic species}

The immobilization of catalytic species within the pores of MOFs is not limited to nanoparticles. One of the first demonstrations of this was the utilization of zeolite-like rho-ZMOF as a host for large catalytically active metalloporphyrins. Here, a free-base porphyrin was encapsulated by the rho-ZMOF to produce a versatile platform. This allowed for post-synthetic metallation with various transition metal ions to produce a wide range of encapsulated metalloporphyrins. For example, MnRTMPyP was successfully explored as a catalyst for cyclohexane oxidation. ${ }^{147]}$

In the same spirit, the encapsulation of enzymes is an emerging field. Through direct reaction of zinc nitrate, 2-methylimidazole and cytochrome c in methanol, Cyt c@ZIF-8 composite was obtained. The apparent activity of Cyt $c$ in ZIF-8 was increased by 10 -fold, compared to its native counterpart in solution. ${ }^{[148]}$ Microperoxidase was the first enzyme to be immobilized in a MOF post-synthetically. A mesoporous Tb-mesoMOF contains nanoscopic cages, which provide sufficient space for the enzyme. The immobilization was achieved by immersing the freshly synthesized MOF in microperoxidase solution in 4-(2hydroxyethyl)-1-piperazineethanesulfonic acid buffer. ${ }^{[149]}$ The recent work in this field holds great promise and offers new insights into the use of MOFs as enzyme immobilization platforms ${ }^{[150]}$

\subsection{MOFs as precursors to catalytic composite materials}

A novel approach of developing catalysts by MOF mediated synthesis was established in the past five years. This approach is based on heat treatment, typically in an inert gas atmosphere. ${ }^{[151]}$ Here, MOFs act as catalyst precursors and the treatment leads to the formation of nanoparticles with high loading and uniformity embedded in a carbon matrix. ${ }^{[152]}$ The first reported example of such a catalyst involves pyrolysis of Fe-based Basolite F300. This seemingly facile method allowed for formation of highly loaded (40 wt\%) uniform iron carbide particles embedded in a microporous carbon, resolving the well-known challenge of trade-off between nanoparticle loading and their size. The obtained solid was tested in the Fischer-Tropsch process, where it showed striking activity and stability. ${ }^{[133]}$ This approach was pushed further by silica condensation within the ZIF-67 framework which was followed by pyrolysis and subsequent calcination. The resulting solid comprised highly loaded, uniform cobalt nanoparticles supported on silica, which acted as an active and stable catalyst in the lowtemperature Fischer-Tropsch process. ${ }^{[153]}$

\subsection{Electrocatalysis}

The first example of electrocatalysis in MOFs was shown for the framework $\left[\mathrm{Cu}_{2}(\mathrm{bpdc})_{2}(\mathrm{Dpq})_{2}\left(\mathrm{H}_{2} \mathrm{O}\right)\right] \mathrm{H}_{2} \mathrm{O}$ in the electrocatalytic reduction of bromate, nitrite and hydrogen peroxide. The electrode was fabricated by mixing the MOF and graphite powders in a mortar with paraffin oil and packing a tube with a mixture. ${ }^{[154]}$ This field is being actively explored with major efforts being devoted to the issue of framework stability. At the same time, nanoparticles based electrocatalysts obtained by MOF-mediated synthesis are being actively used. ${ }^{[122]}$

\subsection{Photocatalysis}

A uranium-nickel-organic hybrid compound with micropores was the first metal-organic porous solid that showed photocatalytic activity for the degradation of methyl blue as a model pollutant. ${ }^{[155]}$ Today, a major emphasis lies on the investigation the tunable ligand to metal charge transfer in MOFs. MOF photocatalysts have successfully been tested in a variety of reactions, starting from UV-driven dye-oxidation, to hydrogen and oxygen evolution reactions. ${ }^{[122]}$ Although, MOFs' applicability in the industry is still in its infancy, their unique functionality inspires their utilization as heterogeneous catalysts.

\section{Biomedical Applications}

The unique characteristics and enormous compound space of reticular frameworks provide various opportunities for its utilization in the biomedical field. The design flexibility, tunable properties, high porosity and modular assembly can be tailored ideally to specific applications. Leveraging these characteristics, MOFs have been successfully applied in drug delivery, imaging, radio- and photo-therapy applications resulting in numerous impactful publications (Figure 6). ${ }^{[156-158]}$ 


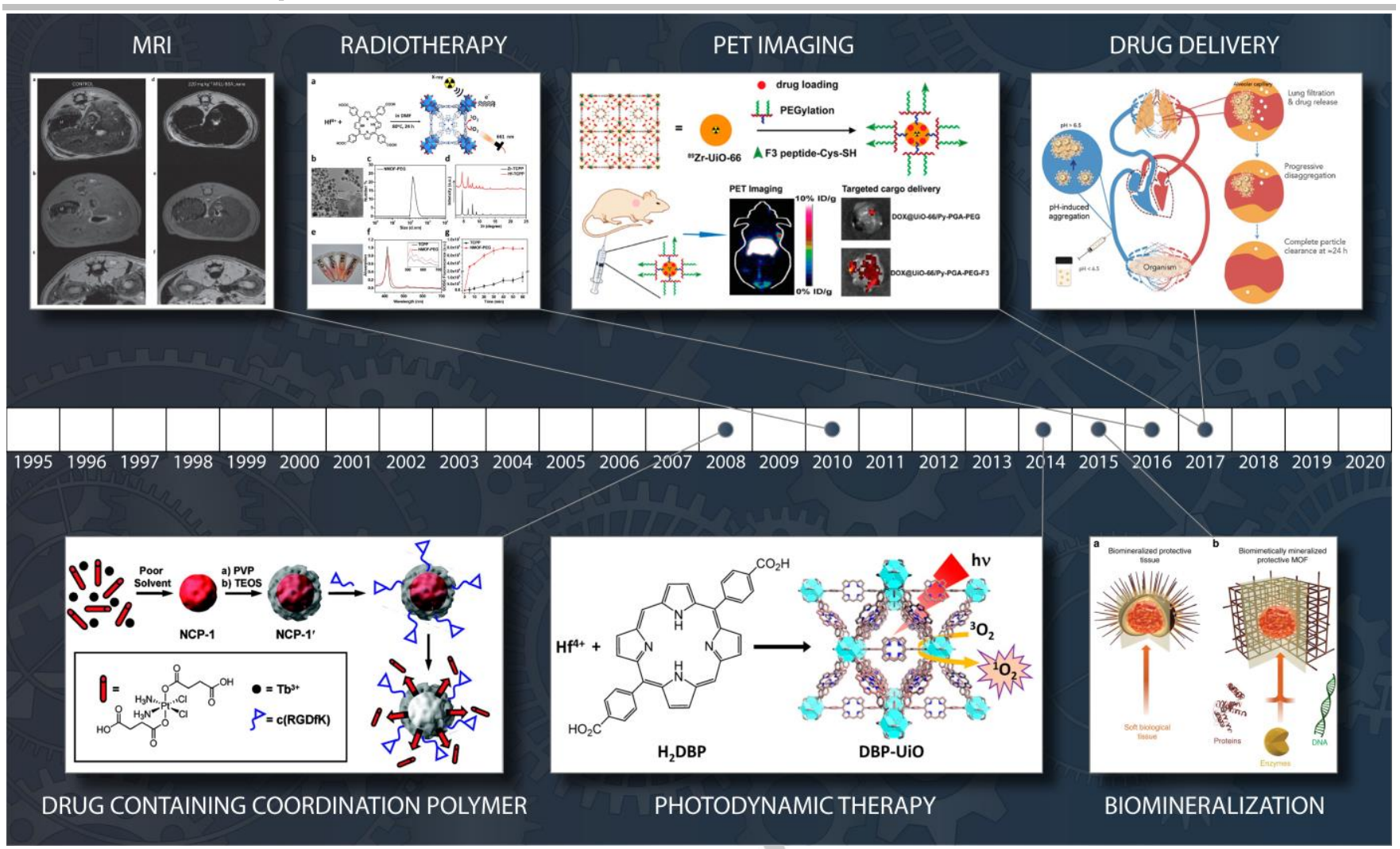

Figure 6. Illustrative timeline of the milestones in the biomedical field. Drug containing coordination polymers (Reprinted with permission from ref. [159]. Copyright 2008 American Chemical Society). MRI (Reprinted with permission from ref. ${ }^{[160]}$. Copyright 2009 Nature Publishing Group). Photodynamic therapy (Reprinted with permission from ref. ${ }^{[161]}$. Copyright 2014 American Chemical Society. Requests for permissions related to the material should be directed to the ACS). Biomineralization (Reprinted from ref. ${ }^{[162]}$. Published under the Creative Common CC BY license). Radiotherapy (Reprinted with permission from ref. ${ }^{[163]}$. Copyright 2016 Elsevier). PET Imaging (Reprinted with permission from ref. ${ }^{[164]}$. Copyright 2017 American Chemical Society). Drug delivery (Reprinted with permission from ref. ${ }^{[165]}$. Copyright 2017 Wiley - VCH).

\subsection{MRI}

An early biomedical application of reticular framework nanoparticles took advantage of the high metal content of nanoscale MOFs: it explored their utilization as magnetic resonance imaging (MRI) contrast agents. ${ }^{[157,158]}$ Since a high concentration of conventional contrast agents is essential for sufficient contrast enhancement, MOFs provided the basis for highly favorable alternatives due to their large loading capacity of magnetic centers. Pioneering work confirmed the possibility of generating $\mathrm{Gd}^{3+}$-containing nanoscale MOFs with favorable MRI contrast agent activity. ${ }^{166]}$ Crystalline nanorods of $\mathrm{Gd}(\mathrm{BDC})_{1.5}\left(\mathrm{H}_{2} \mathrm{O}\right)_{2}$ and nanoplates of $\left[\mathrm{Gd}(1,2,4-\mathrm{BTC})\left(\mathrm{H}_{2} \mathrm{O}\right)_{3}\right] \cdot \mathrm{H}_{2} \mathrm{O}$ with high $\mathrm{Gd}^{3+}$ content and very large relaxivities per particle were generated, which even outperformed $\mathrm{Gd}^{3+}$ containing liposomes or the clinically established MRI contrast agent OmniScan. Several developments of Gd-based nano MOFs have followed. ${ }^{[167]}$ Unfortunately, the release of toxic $\mathrm{Gd}^{3+}$ from the firstgeneration MRI MOFs prevented clinical translation. Owing to the principles of reticular chemistry and modular assembly of MOFs, MR-active nano-MOFs could be generated based on better tolerable $\mathrm{Mn}^{2+}$ or $\mathrm{Fe}^{3+} \cdot{ }^{[160,168]}$ Another approach is to load the high surface area nanoparticles with clinically approved contrast agents to path the way for theranostic applications. ${ }^{[169]}$

\subsection{Computed tomography}

Computed tomography (CT) is another widely used imaging technique in which MOFs with high electron density and X-ray attenuation can be generated by using organic linker derivatives as well as SBUs containing high-Z elements. The iodinated terephthalic acid derivative 2,3,5,6-tetraiodo-1,4benzenedicarboxylic acid was used as an organic linker in nanoscale coordination polymers (NCPs) with $\mathrm{Cu}^{2+}$ and $\mathrm{Zn}^{2+}{ }^{2}{ }^{[170]}$ The Hounsfield unit $(\mathrm{HU})$ measures the $x$-ray attenuation of a material in relation to water $(0 \mathrm{HU})$. The Cu- (NCP 3a, 4653 \pm 520 $\mathrm{HU} \mathrm{M}^{-1}$ ) and $\mathrm{Zn}$-based (NCP 5b, 4513 $\pm 408 \mathrm{HU} \mathrm{M}^{-1}$ ) coordination polymers exhibited an iodine content of $63 \mathrm{wt} \%$ and x-ray attenuation coefficients comparable to the clinically established contrast agent lodixanol $\left(3840 \pm 560 \mathrm{HU} \mathrm{M}^{-1}\right)$ in side-by-side phantom studies. Nanoscale MOFs with the UiO-66 structure containing $\mathrm{Zr}$ (atomic number 40) or $\mathrm{Hf}$ (atomic number 72) as SBUs were generated as a complementary strategy for $x$-ray attenuation enhancement. ${ }^{[171]}$ Direct comparison of $\mathrm{Hf}-\mathrm{UiO}$ (10740 HU M${ }^{-1}$ ) and $\mathrm{Zr}-\mathrm{UiO}\left(5600 \mathrm{HU} \mathrm{M}^{-1}\right.$ ) with lodixanol (5390 $\mathrm{HU} \mathrm{M}^{-1}$ ) confirmed the suitability for contrast enhancement.

\subsection{Positron emission tomography}

The highly flexible design and modular nature of reticular frameworks also facilitates the replacement of metal nodes in MOFs by positron-emitting radioisotopes, which can be detected by positron emission tomography (PET). The principles of 
reticular chemistry enabled the straightforward adaption of MOFs to PET imaging applications: the chemically stable and highly porous nanoscale MOF UiO-66 was generated with the positronemitting ${ }^{89} \mathrm{Zr}$ instead of the conventional $\mathrm{Zr}$ isotopes. ${ }^{[164]}$ The intrinsically radioactive UiO-66 nanoparticles contained a high load of the anti-cancer drug doxorubicin and became further functionalized with PEG as well as a tumor-targeting peptide ligand F3. After intravenous injection in mice, PET imaging showed a fast accumulation of MOF nanoparticles in the liver and spleen. In this case, not only the presence of embedded components was utilized, but also the supramolecular characteristics were essential to load drugs into the reticular framework matrix.

\subsection{Photodynamic therapy and radiotherapy}

The use of functional components as building units for the assembly of intrinsically active reticular frameworks has also been used for other therapeutic strategies beyond drug delivery, including photodynamic therapy (PDT) and radiotherapy (RDT). For these purposes, the reticular frameworks contain components that absorb exogenous energy, light, or x-rays and convert it into local therapeutic effects. PDT requires photosensitizers, which induce ROS generation upon light exposure. ${ }^{[172]}$ Hematoporphyrin is considered a first-generation photosensitizer being used for PDT of cancers since the 1970s. ${ }^{[172]}$ Carboxylic acid-containing porphyrin derivatives, such as 5,15-di(p-benzoato)porphyrin (H2DBP), ${ }^{161]}$ 5,15-di(p-benzoato)-chlorin $\quad(\mathrm{H} 2 \mathrm{DBC})^{[173]}$ or tetrakis(4-carboxyphenyl)-porphyrin (TCPP) ${ }^{[174,175]}$ have been used as organic linker components in photosensitizing MOFs. The planar macrocyclic carboxylic acid linkers assemble into MOFs with $\mathrm{Hf}^{4+}$ (DBP-UiO, DBC-UiO, Hf-TCPP NMOF), ${ }^{[161,173,176]}$ $\mathrm{Zn}^{2+}(\mathrm{SO}-\mathrm{PCN})^{[174]}$, or $\mathrm{Zr}^{4+}(\mathrm{PCN}-224)^{[175]}$ with significant PDTmediated antitumoral effects in vitro and in vivo. For the enhancement of radiotherapy, nanoparticles containing high Zelements have been investigated. These can interact with ionizing radiation and release free radicals to the local environment. ${ }^{[163]}$

\subsection{Drug delivery}

Reticular frameworks can exhibit extraordinarily high porosity and capacity for the storage of guest molecules. In the field of drug delivery, a high drug loading capacity is a generally aspired parameter of drug carriers. The first utilization of highly porous reticular frameworks as drug carriers was demonstrated with MIL$100(\mathrm{Cr})$ and MIL-101(Cr). ${ }^{[177]}$ The mesoporous MOFs with huge pores (25-34 $\AA$ ) and high surface areas (3100-5900 $\left.\mathrm{m}^{2} \mathrm{~g}^{-1}\right)$ were loaded with the analgesic model drug ibuprofen (IBU). Both materials exhibited remarkably high drug adsorption of $0.35 \mathrm{~g}$ (MIL-100) and $1.38 \mathrm{~g}$ (MIL-101) IBU per gram dehydrated MOF and a sustained release over three (MIL-100) to six (MIL-101) days due to host-guest interactions (electrostatic, $\pi-\pi$ ). To circumvent chromium mediated toxicity drug vehicles, iron(III) carboxylate MOFs, such as MIL-53, MIL-88A, MIL-88B, MIL-89, MIL-100, and MIL-101_ $\mathrm{NH}_{2}$, were utilized as better tolerated alternatives with combined drug delivery and MRI contrastenhancing capabilities. ${ }^{[160]}$ The favorable loading and release profiles of MIL-100(Fe) have been demonstrated in several cases, such as busulfan, azidothymidine triphosphate, doxorubicin, cidofovir, caffeine, urea, fluorescein, gentamycin, and gemcitabine monophosphate (GMP). ${ }^{[160,165]}$ Due to a characteristic reversible aggregation behavior in the in vivo environment, MIL-100(Fe) demonstrated a remarkable potential to accumulate in the lung and release of the anticancer drug GMP upon $\mathrm{pH}$ change with significant therapeutic effects on experimental tumors. ${ }^{[165]}$

Inspired by the natural process of biomineralization, in situ embedding into specific MOFs during framework assembly was developed as an option for the internal encapsulation of biomolecules under mild synthesis conditions and preserved biological function. ${ }^{[162]}$ The strategy was demonstrated with ZIF-8, HKUST-1, Eu/Tb-BDC, and MIL-88A. It was found that an interaction between biomolecules and MOF building blocks causes local concentration in solution, nucleation of MOF crystals, and affect the size, morphology and crystallinity. Embedded proteins are protected from harsh environments, such as exposure to proteolytic agents, boiling water or DMF. The strategy was utilized and extended for the cellular delivery of different types of biomolecules. Proteins ${ }^{[178,179]}$, DNA ${ }^{[180,181]}$, siRNA, ${ }^{[182]}$ and Cas9/sgRNA ribonucleoproteins ${ }^{[183]}$ were encapsulated into ZIFs, which are stable at physiological $\mathrm{pH}$ but disassemble in the mildly acidic environment of endo-lysosome and promote release from the intracellular vesicles. Whole cells were embedded into presynthesized MOF nanoparticle matrices. UiO-66, UiO-66- $\mathrm{NH}_{2}$, UiO-66-OH, UiO-67, and MOF-808 were demonstrated to be suitable additives for embedding and cryopreserving red blood cells during freezing and thawing processes. ${ }^{[184]}$ ZIF-8, MIL-100, UiO-66- $\mathrm{NH}_{2}$, and MET-3-Fe MOF nanoparticles were used for the encapsulation and protection of living mammalian cells. ${ }^{[185]}$ These 'SupraCells' persisted in a viable, non-replicative 'spore-like' state and resisted extreme conditions, such as osmotic stress, reactive oxygen species (ROS), $\mathrm{pH}$ and UV light exposure. Upon disruption of the MOF exoskeleton by metal chelation, the cells returned to their native replicative state.

Despite remarkably high drug loading capacities, reticular framework chemistry has also enabled tuned and dynamic cargo release in response to external stimuli. Table S3 summarizes examples of drug release profiles achieved by specific MOF architectures.

\subsection{MOF-based clinical trials}

The rapid progress in the development of safe and effective therapeutic reticular frameworks led to the initiation of the first clinical trials in 2018. The 'Radio-immuno Metal-Organic' (RiMO) compound RiMO-301 (Rimo Therapeutics Inc.) was the first therapeutic MOF compound administered to human patients in a Phase I clinical trial. ${ }^{[8]}$ The intrinsically nontoxic RiMO-301 scaffold enhances the efficacy of X-ray radiotherapy by serving as a radio-sensitizing agent after intratumoral injection and irradiation. In a short period of time, two additional antitumoral nanoscale coordination polymers CPI-100 and CPI-200 (Coordination Pharmaceuticals, Inc.) followed and entered firstin-human clinical trials. Phase I studies are intended to evaluate the safety, tolerability and pharmacokinetics of $\mathrm{CPI}-100$ and $\mathrm{CPI}$ 200 in patients with advanced solid tumors. ${ }^{[8]}$

Reticular chemistry has demonstrated that the highly flexible and modular assembly from a large number of suitable building units allows for precise tuning of frameworks for specific biomedical applications. In many cases, each component serves an individual purpose, despite creating a passive material scaffold. A high degree of functionality, as well as the facile synthesis by 
self-assembly is desirable to achieve a high 'multifunctional efficiency' and to minimize patient exposure to excessive unfunctional material during biomedical applications. ${ }^{[186]}$ It is expected that reticular chemistry will continue to have a high impact on biomedicine and will originate new nanopharmaceuticals entering clinical trials and the market at the end.

\section{Chemical Sensing}

The same qualities that make MOFs and COFs promising candidates for adsorption and separation applications enable them to realize sensitive and selective chemical sensors. The combination of their microporous nature, large internal surface area, and tailorable pores enable a high uptake, even at low concentrations, and results in a steep sensor response curve. Their potential for selective uptake was identified early on: first, by the preferential adsorption of aromatic over non-aromatic solvents, ${ }^{[187]}$ and shortly after by the size-dependent inclusion of alcohols $^{[188]}$

This section highlights the major achievements in the integration of MOFs and COFs into chemical sensors (Figure 7). The selected milestones underline the more mature state of MOFbased gas and vapor sensing, compared to detection in the liquid phase and COF-based sensors in general. To acknowledge pioneering work and to outline the evolution of the field, first demonstrations and current records are listed in Table S4 for each type of sensor. Although MOF-based sensors have evolved dramatically over the past two decades, challenges remain on the road to real-world applications. In particular, the enhancement of the sensor selectivity in a complex background, which is often claimed as an area where MOFs and COFs could provide an edge over commercial sensors, still needs to be fully demonstrated, as most studies do not include (realistic) interferents.

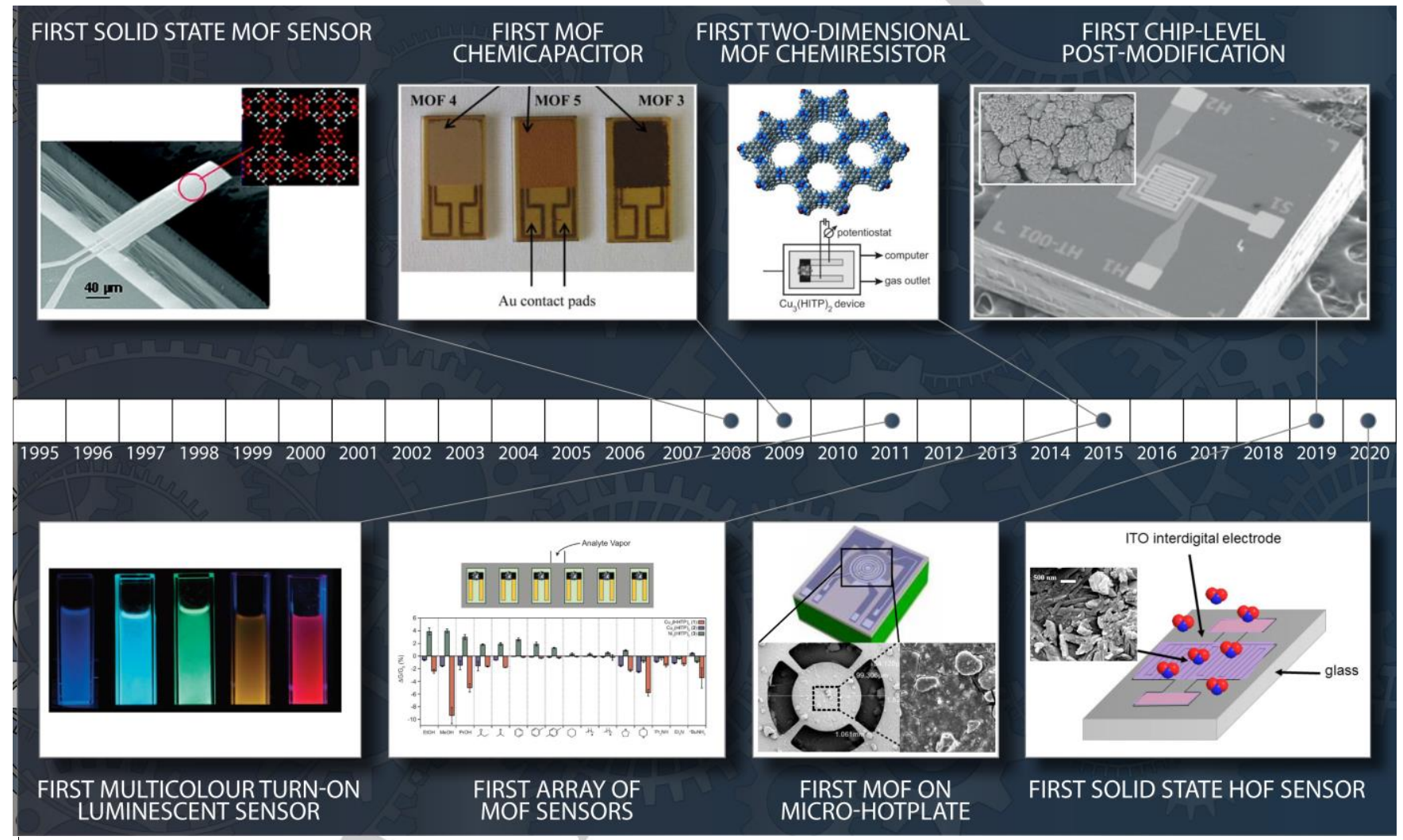

Figure 7. Illustrative timeline of the milestones in the chemical sensing field. First solid state MOF sensor (Reprinted with permission from ref. ${ }^{[189]}$. Copyright 2008 American Chemical Society). First MOF chemicapacitor (Reprinted from ref. ${ }^{[190]}$. Published under the Creative Commons Attribution license). First multicolour turnon luminescent sensor (Reprinted with permission from ref. ${ }^{[191]}$. Copyright 2011 Springer Nature) First two-dimeznsional MOF chemiresistor (Reprinted with permission from ref. ${ }^{[192]}$. Copyright 2015 Wiley - VCH). First array of MOF sensors (Reprinted with permission from ref. ${ }^{[193]}$. Copyright 2015 American Chemical Society). First MOF on micro-hotplate (Reprinted from ref. ${ }^{[194]}$.). First chip-level post-modification (Reprinted with permission from ref. ${ }^{[195]}$. Copyright 2019 Wiley VCH). First solid state HOF sensor (Reprinted with permission from ref. ${ }^{[196]}$. Copyright The Royal Society of Chemistry 2020 ).

\subsection{Optical sensors}

The earliest observation of sensing in MOFs might have been the color change of HKUST-1, from turquoise to green, upon the exchange of $\mathrm{Cu}^{2+}$-coordinated water with pyridine. ${ }^{[197]}$ Although the integration and miniaturization of such solvatochromic sensors are not trivial, an elegant approach has been demonstrated by placing a MOF thin film between an LED and a photodiode to constitute a humidity sensor ${ }^{[198]}$, and much later an $\mathrm{NO}_{2}$-specific calixarene-based sensor. Luminescent sensors transduce uptake as changes in emission intensity. As sensing often occurs through quenching by the target (i.e., turn-off mechanism), detecting ultra-low concentrations is challenging and prone to interference. Solvatochromic or luminescent responses are highly dependent on both the target (e.g., electronrich groups, as encountered in nitro-aromatic explosives) and the 
MOF (e.g., lanthanide-based). In some cases, this specificity can enable differentiation of guests based on their distinct interactions, as illustrated by the multicolor luminescent turn-on response of an interpenetrated naphthalenediimide (NDI) framework to differently substituted aromatics. ${ }^{[191]}$

In most cases, however, the analyte or the best-suited microporous material preclude a color-change or luminescent response. The development of a broadly applicable sensing technology requires a transduction principle that functions irrespective of the host-guest combination. For instance, the refractive index of any activated porous solid will increase upon adsorption of any guest. In thin films, this change can be monitored in multiple configurations, ranging from scientific instruments to integrated sensors. Ellipsometric porosimetry has been used to study adsorption in porous thin films for over two decades in the microelectronics community and was first demonstrated in MIL-101 films using alcohol probes. ${ }^{[199]}$ Refractive index changes can also be transduced in a simpler transmission measurement, as demonstrated in the first interferometric sensor, a ZIF-8 Fabry-Pérot etalon. ${ }^{[200]}$ To enhance the response of such interference-based sensors, MOF layers can be alternated with either oxides or air gaps to enable photonic crystals with a regular structure and a high refractive index contrast. ${ }^{[201]}$ Somewhat related is the use of patterned films that function as responsive diffraction gratings, a concept introduced two decades ago, ${ }^{\text {[202] }}$ and implemented for MOFs in different ways. ${ }^{[203]}$ Alternatively, refractive index changes can be transduced via the evanescent field in MOF films coated on optical resonators, fibers, or plasmonic structures. The first microring resonator coated with ZIF-8 did not only feature a low detection limit but also demonstrated an integrated optical circuit for the in- and out-coupling of light, ${ }^{[204]}$ a common obstacle for optical sensors.

\subsection{Electromechanical sensors}

Because of their material- and analyte-agnostic transduction, electromechanical sensors have been widely explored for MOFs. A quartz crystal microbalance (QCM) is the simplest implementation of this sensor class, and was demonstrated already three decades ago for zeolite thin films. ${ }^{[205]}$ Although QCMs suffer from environmental factors (e.g., temperaturerelated drift), the first MOF sensor start-up, Matrix Sensors, uses QCMs for the detection of $\mathrm{CO}_{2}$ and $\mathrm{CH}_{4}{ }^{[206]}$ Surface acoustic wave (SAW) sensors can have a sensitivity orders of magnitude higher than QCMs and are well-suited for device integration. ${ }^{[207]}$ Similarly compatible with microfabrication are microcantilevers, which can be operated either in 'dynamic mode' by monitoring frequency shifts or 'static mode' by measuring the degree of bending of a non-vibrating cantilever. The first solid-state MOFbased sensor was of the latter type and transduced the bending stress in a MOF film resulting from small adsorption-induced changes in the unit cell. ${ }^{[189]}$

\subsection{Chemiresistive sensors}

By far the largest fraction of commercial sensors fall in the category of the chemiresistive sensors and are based on the resistance change upon the reaction of analyte molecules with oxygen chemisorbed on a semiconducting metal oxide surface. Since MOFs are generally electrically insulating, a chemiresistive response is observed only in a few materials. The first MOF chemiresistor used ZIF-67 to detect formaldehyde and required heating up to $150^{\circ} \mathrm{C}$ to reach a high enough conductivity. ${ }^{[208]}$ The discovery of the more conductive two-dimensional MOFs, often based on hexaiminotriphenylene (HITP) and hexahydroxytriphenylene (HHTP) linkers, led to chemiresistors operating at room temperature and capable of detecting $\mathrm{NH}_{3}, \mathrm{NO}$, and $\mathrm{H}_{2} \mathrm{~S}$ in low concentrations. ${ }^{[192]}$ Likewise, two-dimensional COFs have found their way into chemiresistors. ${ }^{[209]}$ As the different modes of charge transport in these two-dimensional materials are better understood, the operating principle of these sensors is elucidated. ${ }^{[210]}$ Such progress opens perspectives on combining control over both material composition and textural properties (e.g., grain boundary density) to fine-tune MOF-based chemiresistors. In a different approach, insulating MOFs can be mixed with conductive materials such as graphene oxide to realize chemiresistive behavior, as in the first conductive composite sensor used for the detection of $\mathrm{NH}_{3} \cdot{ }^{[211]}$ Alternatively, MOFs can be harnessed as filters that determine which molecules reach the oxide surface. In the first illustration of this concept, a ZIF coating on $\mathrm{ZnO}$ nanowires improved the response to acetone in the presence of water vapor, ${ }^{[212]}$ an interferent that chemiresistors commonly struggle with. To boost the sensitivity of commercial chemiresistors, the MOF adsorbent can be separated from the hot sensor surface to reach a maximum analyte loading that is subsequently released all at once by rapid heating. This pre-concentrator approach was demonstrated by depositing HKUST-1 on a micro-hotplate. ${ }^{[213]}$ The MOF showed a higher preconcentration effect compared to Tenax® TA, a state-of-the-art polymer adsorbent, and enabled ppb-level benzene detection.

\subsection{Electrochemical sensors}

In voltammetric and amperometric electrochemical sensors, a waveform or constant potential drives the reaction of the analyte at or near an electrode to generate an output current. For MOFs, this approach was first described using $\left[\mathrm{Cu}(\mathrm{adp})(\mathrm{BIB})\left(\mathrm{H}_{2} \mathrm{O}\right)\right]_{\mathrm{n}}(\mathrm{BIB}$ $=$ 1,4-bisimidazolebenzene and $\mathrm{H}_{2}$ adp = adipic acid) as an electrocatalytic-active compound, deposited on carbon electrodes (GCEs) for the detection of $\mathrm{H}_{2} \mathrm{O}_{2} \cdot{ }^{[214]}$ The further development of this method resulted in the fabrication of the first flexible MOF sensors based on screen printing for the voltammetric in vivo detection of nutrients. ${ }^{[215]}$ Potentiometric sensing, in which the electrode potential is monitored at zero current, is limited to one recent example in which HTTP-based MOFs covered with an ionselective membrane were used for the detection of $\mathrm{NO}_{3}{ }^{-}$and $\mathrm{K}^{+}$ ions. ${ }^{[216]}$

\subsection{Chemicapacitors}

Chemicapacitors measure the increase in dielectric constant upon guest adsorption in an electrically insulating porous solid. Because of their ease of fabrication, interdigitated electrodes (IDEs) coated with a relatively thick MOF film $(>1 \mu \mathrm{m})$ have mostly been used, even though the output of such sensors inevitably contains a stray substrate contribution. Alternatively, parallel-plate (PP) capacitors, in which the porous material is sandwiched in between two electrodes, enable a response that is several times larger when the dielectric is sufficiently thin. Thus far, this advantage of PP chemicapacitors has not yet been realized for MOFs or COFs because of the requirement for high- 
quality films without pinhole defects. In the first report on chemicapacitors, both IDEs and PP electrodes were explored via screen printing and pellet pressing of different MOF powders. ${ }^{[190]}$ The further development of MOF-based IDE chemicapacitors, resulted, for instance, in the design of a selective $\mathrm{SO}_{2}$ sensor with an ultra-low detection limit, ${ }^{[217]}$ the demonstration of on-chip tailorability of the MOF adsorption properties, ${ }^{[195]}$ their integration with micro-hotplates ${ }^{[194]}$ and enabled the first capacitive sensors based on COFs. ${ }^{[218]}$ Since the magnitude of the capacitive response depends on the dielectric constant of the analyte, the co-adsorption of interferents with a high dielectric constant (e.g., water) can be more pronounced compared to other sensor types (e.g., mass-based). ${ }^{[219]}$

\subsection{ChemFETs}

A different approach to transduce adsorption in electrically insulating MOFs is via the work function of a MOF-coated metal electrode. In most studies based on this principle, strong work function changes have been recorded via Kelvin probe measurements, and allow for specific analyte-MOF combinations a ppb-range detection limit. ${ }^{[220]}$ However, since a Kelvin probe setup cannot be efficiently miniaturized, gas sensors based on work function changes are realized as chemically sensitive fieldeffect transistors (ChemFETs). So far, only two designs based on MOFs have been proposed, involving MOFs as active layer ${ }^{[221]}$ and selective filter in organic ChemFETs. ${ }^{[222]}$ Although this type of sensor promises several advantages, including signal amplification through the transistor characteristics, the underlying mechanism causing the work function shift is not well understood. Future work will elucidate the relative contributions of the capacitive and work function in the ChemFET response, the importance of the dipole moment and charge transfer characteristics of the adsorbed guests, the crystallographic orientation of the film, and the properties of the MOF-electrode interface and grain boundaries in the MOF film.

\subsection{Sensor arrays}

Although MOFs and COFs seem excellent candidates for selective sensing, ${ }^{[217,223]}$ it is overly optimistic to aim for perfect selectivity for the analyte over all relevant interferents. Most studies that demonstrate a higher response for the analyte compared to interferents, test each compound separately. Of course, in real-world applications, the sensor would be exposed to all compounds simultaneously, including some interferents present in much higher concentrations than the analyte (e.g., water vapor). Rather than pursuing a single ideal sensor, one way to deal with the selectivity challenge is to combine cross-sensitive sensors into an array, or 'electronic nose' (e-nose). When the combined response of the array contains enough non-correlated information, an analyte of interest can be monitored in a complex background with the help of chemometric data analysis. The enose concept was first explored for MOFs by pooling the separately measured luminescent responses of $[\ln (\mathrm{OH})(\mathrm{bdc})]_{n}$ and MOF-5 to different organics. ${ }^{[224]}$ The first integrated e-nose consisted of an array of 2D MOF chemiresistors with different metal nodes and organic linkers. ${ }^{[25]}$ In both cases, principal component analysis (PCA) allowed distinguishing the pure components. Recently, MOF-based QCM e-noses were also demonstrated, which distinguished binary mixtures of odor molecules using three Cu-MOFs, as well as different enantiomers using a selection of six chiral and achiral MOFs. ${ }^{[226]}$ Due to the large number of MOFs to choose from and the even larger number of ways they can be combined into arrays, computational design principles have been introduced that can advise on the optimal combination of array elements for a specific application. ${ }^{[227]}$ Despite the success of arrays, alternative approaches such as multivariable sensors have been suggested. [228]

The development of new MOFs and COFs, as well as the introduction of new materials such as hydrogen-bonded frameworks (HOFs), ${ }^{[229]}$ will continue to have an impact on the sensing field. The higher added value of small quantities of these materials in sensors compared to bulk applications alleviates the cost restraints for candidate materials, thus leaving a much broader selection. To leverage the potential of these materials in an attractive sensor platform, both, thin films deposition techniques and patterning strategies, are needed. ${ }^{[230]}$ Moreover, in the context of microelectronics, MOFs and COFs can be considered relatively delicate in terms of chemical, mechanical and thermal stability, potentially leading to issues in the processing steps following the deposition of the porous material. These considerations become critical when considering the microfabrication of arrays consisting of multiple MOF- or COFcoated sensor elements.

\section{Electronic and Ionic Conduction}

In the past two decades, reticular materials have proven to be excellent candidates for batteries, ${ }^{[231]}$ supercapacitors, ${ }^{[232]}$ fuel cells, ${ }^{[233]}$ and other devices ${ }^{[234-238]}$ that require some combination of electronic and ionic conductivity. Here, we try to understand what makes MOFs stand out among other reticular systems in the context of electronic and ionic conduction (Figure 8, Table S5).

Conceptually, both electronic and ionic conduction simply provide pathways for electrical current to pass through a material. Yet, these two phenomena are remarkably different at the fundamental level and share little in terms of mechanistic details, physical models, or material design philosophy. Thus, this chapter will be separated into two sections, discussing the achievements in MOF-based electronic and then ionic conductors.

As the goal of this chapter is expositional and not to provide a comprehensive review of MOF conductors, we will focus on several key features of these materials, such as porosity, choice of linkers and metals, and how they impact their charge transport performance - as well as, in some cases, how these features can be controlled through reticular tuning towards improved performance. For comprehensive reviews of the conductive MOF literature, we direct the reader to refs. ${ }^{[239-242]}$. 


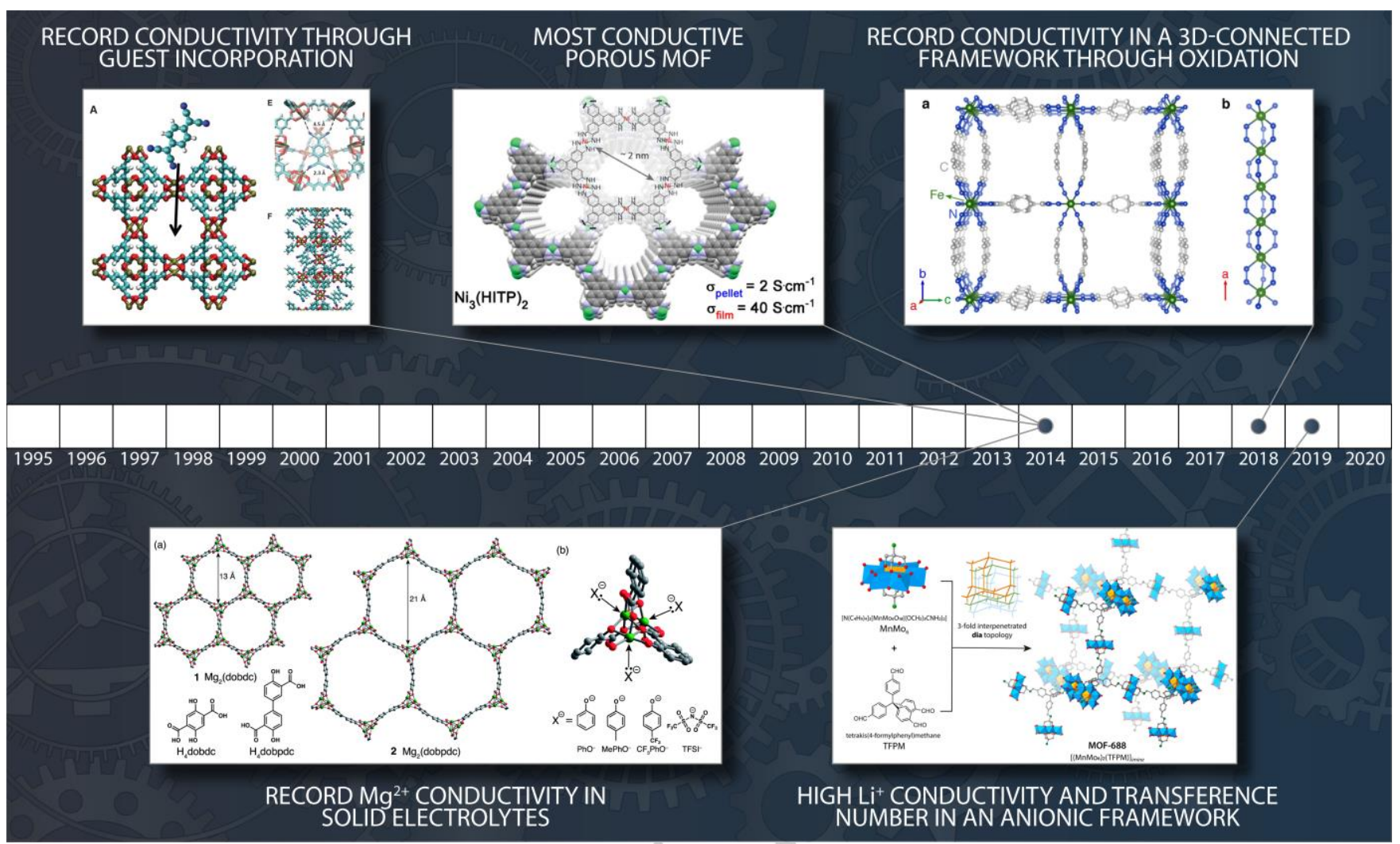

Figure 8. Illustrative timeline of the milestones in the electronic and ionic conduction field: Record conductivity through guest incorporation in HKUST-1 (Reprinted with permission from ref. ${ }^{[243]}$. Copyright 2014 The American Association for the Advancement of Science). $\mathrm{Ni}_{3}(\mathrm{HITP})_{2}-$ highest electrical conductivity in a porous MOF (Reprinted with permission from ref. ${ }^{[244]}$. Copyright 2014 American Chemical Society). Record-setting $\mathrm{Mg}^{2+}$ conductivity in Mg $2(\mathrm{DOBPDC})$ and Mg 2 (DOBDC) (Reprinted with permission from ref. ${ }^{[245]}$. Copyright 2014 The Royal Society of Chemistry; permission conveyed through Copyright Clearance Center, Inc.). High electronic conductivity in a 3D-connected MOF - $\mathrm{Fe}_{2}(\mathrm{BDT})_{3}$ (Reprinted with permission from ref. ${ }^{246]}$. Copyright 2018 American Chemical Society). High Li conductivity in an anionic framework - MOF-688 (Reprinted with permission from ref. ${ }^{[247]}$. Copyright 2019 American Chemical Society).

\subsection{MOFs as electronic conductors}

Electronic conductivity is a desirable characteristic for a variety of important applications: conductive electrodes in batteries and capacitors allow faster (and higher power) charge storage and recovery; ${ }^{[232,248]}$ electrocatalysts can be used without any conductive binder ${ }^{[234]}$ conductive materials allow chemiresistive sensors ${ }^{[238]}$ to achieve viable device resistances. The promise of these applications inspired a rapid expansion of studies focused on imparting electronic conductivity to MOFs in the past decade, achieving such remarkable values as $150 \mathrm{~S} \mathrm{~cm}^{-1}-$ on par with graphite. ${ }^{[249]}$

Classical reticular materials, such as the IRMOF family, ${ }^{[250]}$ are generally poor electronic conductors and feature many elements often deemed unfavorable ${ }^{[251]}$ for electron transport: large pores, predominantly ionic metal-ligand bonds, and lack of redox-active moieties to introduce free carriers or allow charge hopping. Below, we discuss how emerging trends in reticular tuning can address the structural and electronic requirements for charge and ion transport in MOFs.

\subsubsection{Porosity}

MOFs are best known for their large guest-accessible voids, however, the pores complicate electronic transport because they can interrupt the flow of electric current. The usual strategy to counter this issue is to target frameworks with continuous lowdimensional charge transport pathways, which would allow charges to move while avoiding the insulating pores.

Generally, three types of such pathways are implemented in MOFs. The first is the so-called "through-bond" pathway, where extended chains similar to fragments of condensed inorganic structures are responsible for the transport of electrons. The second is the "through-space" pathway, where the transport of electrons is promoted through chains of $\pi-\pi$ stacked organic linkers. The third is the "extended conjugation" pathway, where the metal atoms form an extended conjugated system with the linkers. These pathways, with their advantages and disadvantages, are discussed in detail elsewhere. ${ }^{[240]}$

Reticular modification - tuning of the material while maintaining its overall topology - allows us to glimpse into how well these methods have helped alleviate the disadvantages brought about by porosity. Among the pathways above, one that yields especially well to reticular modification is the "through-bond" pathway. Reticular modification typically relies on conserving the SBU of the MOF, while changing the organic linker. One key example is the conductive MOF-74 analogs $\left(\mathrm{M}_{2}\right.$ (DOBDC) and $\mathrm{M}_{2}$ (DSBDC); $\mathrm{H}_{4} \mathrm{DOBDC}=2,5$-dihydroxyterephthalic acid $\mathrm{H}_{4} \mathrm{DSBDC}=2$,5-disulfhydrylterephthalic acid, $\mathrm{M}=$ divalent metal). [252] These materials feature continuous $-\mathrm{O}-\mathrm{M}-$ or $-\mathrm{S}-\mathrm{M}-$ chains that serve as the main pathway for charge transport and extend 
along hexagonal pores. MOF-74 analogs are moderately conductive, with values not exceeding $10^{-6} \mathrm{~S} \mathrm{~cm}^{-1}$. Recent studies have shown significant control over both the porosity of these frameworks and their conductivity through reticular tuning. Importantly, anthracene-incorporated MOF-74 analogs ANMOF$74,{ }^{[253]}$ showed conductivities ranging between $10^{-9}$ and $10^{-7} \mathrm{~S}$ $\mathrm{cm}^{-1}$, similar to the $\mathrm{M}_{2}$ (DSBDC) materials, while achieving considerably higher surface areas of over $1200 \mathrm{~m}^{2} \mathrm{~g}^{-1}$ (vs. 300 $\mathrm{m}^{2} \mathrm{~g}^{-1}$ for activated $\mathrm{M}_{2}$ (DSBDC) materials) due to the longer linkers.

The "extended conjugation"-type MOFs, better known collectively as 2D conductive MOFs, allow less flexibility in reticular tuning because the linker cores must conform to certain symmetries and maintain full conjugation with the functional groups. Indeed, nearly all materials in this class represent layered frameworks based on hexasubstituted triphenylenes and benzenes, with semiquinoid and related moieties serving as the metal-binding functional groups. Owing to their very high electrical conductivity, 2D conductive MOFs have commanded significant attention in the past five years. Despite the apparent synthetic limitations, reticular tuning with these materials is obvious, especially when comparing materials with benzene and triphenylene cores. For instance, moving from $M_{3}$ (benzenehexathiol) $)_{2}$ and $M_{3}$ (hexaiminobenzene $)_{2}$ to the isoreticular, larger-pore $\mathrm{M}_{3}$ (triphenylenehexathiol) ${ }_{2}$ and $\mathrm{M}_{3}$ (hexaiminotriphenylene) ${ }_{2}^{[254]}$ equates to moving from dense structures with surface areas no higher than $100 \mathrm{~m}^{2} \mathrm{~g}^{-1}$ to porous structures with surface areas on the order of $600 \mathrm{~m}^{2} \mathrm{~g}^{-1}$. Electrical conductivities in these materials highlight conflicting trends: whereas the thiolate-based triphenylene MOFs are several orders of magnitude less conductive $\left(10^{-4}-10^{-2} \mathrm{~S} \mathrm{~cm}^{-1}\right)$ than their benzene analogs (up to $160 \mathrm{~S} \mathrm{~cm}^{-1}$ ), the triphenylene MOFs in the iminosemiquinone series, topped by $\mathrm{Ni}_{3}$ (hexaiminotriphenylene) $)_{2}\left(\sim 150 \mathrm{~S} \mathrm{~cm}^{-1}\right),{ }^{[244,249]}$ are significantly more conductive than the benzene materials. Crystallinity, rather than intrinsic electronic or structural effects, likely plays an outsized role here.

Although the attraction and the fundamental challenge is to maintain porosity while increasing conductivity, not all applications require that pores be completely empty. In such cases, guest molecules can promote charge transport. One milestone study involved the incorporation of the classical organic electron acceptor tetracyanoquinodimethane into $\mathrm{Cu}_{3}(1,3,5-$ benzenetricarboxylate) $)_{2}$, which improved the conductivity of the nearly insulating starting material from $2 \times 10^{-9} \mathrm{~S} \mathrm{~cm}^{-1}$ to $0.07 \mathrm{~S}$ $\mathrm{cm}^{-1}$.243] This strategy was subsequently applied with much success to different host structures with such varying guests as $\mathrm{C}_{60},{ }^{[255]}$ polypyrrole, ${ }^{[256]}$ and $\mathrm{I}_{2}{ }^{[257]}$.

\subsubsection{Bonding between linker and metal}

Traditional reticular MOF families are mostly based on multinuclear carboxylate SBUs. These often provide good structural stability and can generate a wide variety of structural motifs. Nevertheless, these SBUs show less promise for making electronically conductive MOFs primarily because of the highly polarized, ionic character of the metal-carboxylate bond. Increased covalency (i.e., electron sharing) between the metal and the linker promotes electron delocalization and thus enhanced charge transport. Testament to this are some of the most exciting MOF electronic conductors:
$\mathrm{Ni}_{3}$ (hexaiminotriphenylene) $)_{2}$ and $\mathrm{Ni}_{3}$ (benzenehexathiol) $)_{2}$, which both feature conductivities in excess of $100 \mathrm{~S} \mathrm{~cm}^{-1}$. $^{[249]}$ Belonging to the "extended conjugation" pathway type, these materials feature two-dimensional (2D) hexagonal layers of trigonal $\pi$ conjugated linkers strongly bound to square-planar $\mathrm{Ni}^{2+}$ ions.

Improving the metal-linker covalency has been the leitmotif in the design of electronically conductive MOFs, featuring prominently in "through-bond" and "extended conjugation"-type materials. This approach to improving MOF conductivity yields especially well to reticular modification via the linkers' functional groups. Typically, this involves exchanging "hard" functional groups, such as carboxylates or phenols into their softer Lewis base analogs, which leads to better energetic overlap with the softer late transition metals commonly used in MOFs. Among the early key-examples of this approach are the aforementioned MOF-74-type $\mathrm{M}_{2}$ (DOBDC) and $\mathrm{M}_{2}$ (DSBDC) materials, which saw a tenfold increase in conductivity upon substitution of the phenolic oxo group for a thiolate. ${ }^{[258]}$ The same concept is often used to rationalize work on iminosemiquinoid and thiolate-based $2 \mathrm{D}$ conductive MOFs. However, although the $\mathrm{N}$ - and S-based MOFs in this class generally tend to be more conductive than their catechol analogs, we are not aware of systematic studies that establish a clear correlation between electrical conductivity and metal-linker covalency in moving from semiquinone to iminosemiquinone, to thiolate. In fact, the highest conductivities in this class are generally shown by the iminosemiquinoid materials, which may be expected to be less conductive than the thiolatebased MOFs on account of metal-ligand covalency alone.

\subsubsection{Redox-active elements}

Electronic conductivity depends critically on the concentration of free carriers. A common approach used to increase the concentration of free carriers, ubiquitous in such materials as organic conductors and metal oxides, is through substoichiometric oxidation or reduction of redox-active elements. The same approach is also used in MOFs to great success and takes inspiration from both the chemistry of organic conductors by borrowing such prominent electroactive fragments as tetrathiafulvalene; ${ }^{[259]}$ as well as from metal oxide chemistry, where easily oxidized metal species, such as Fe(II) are used to create charge carriers.

Controlled increase of charge carrier concentration is limited mostly to post-synthetic oxidation ${ }^{[246,260]}$ or reduction ${ }^{[261]}$ of already present redox-active elements. One milestone example of this is in $\mathrm{Fe}_{2}(\mathrm{BDT})_{3}\left(\mathrm{H}_{2} \mathrm{BDT}=5,5^{\prime} \quad-(1,4-\right.$ phenylene $)$ bis $(1 \mathrm{H}$-tetrazole $)$ ). This framework, featuring continuous $-\mathrm{N}-\mathrm{Fe}-\mathrm{N}-$ chains as the main pathway for charge transport, is only moderately conductive as synthesized (below $10^{-4} \mathrm{~S} \mathrm{~cm}^{-1}$ ) due to the iron sites being purely $\mathrm{Fe}(\mathrm{II})$. Prolonged exposure of the material to air, however, leads to partial oxidation of the iron sites into a mixed $\mathrm{Fe}(\mathrm{II} / \mathrm{III})$ state, injecting free carriers into the materials and leading to a $10^{4}$ fold increase in conductivity, up to an impressive value of 1.2(4) $\mathrm{S} \mathrm{cm}^{-1}$. ${ }^{246]}$

\subsection{MOFs as ionic conductors}

Although ionic conductivity may and often does coexist with electronic conductivity, the study of ionic conductors is typically focused on materials, which carry electrical current primarily or exclusively through the movement of ions and not electrons or 
holes. This is due to the main applications of ionic conductors: solid-state electrolytes or ion membranes that must be electronic insulators. Solid-state electrolytes are of critical importance in a variety of energy generation and storage devices, most prominently metal-ion batteries and fuel cells. Both of these require low electronic conductivities $\left(<10^{-10} \mathrm{~S} \mathrm{~cm}^{-1}\right)$ to prevent current leakage or, in the case of batteries, lower the selfdischarge rate. ${ }^{[262]}$ The study of MOFs as ionic conductors generally focuses on cation transport and separates specifically proton conductors from other ions as protons are sufficiently dissimilar from the other cations with regard to their transport properties. Although proton conductivity is perhaps the most developed subfield within ionically conductive MOFs, we cannot hope to capture its full diversity in such a brief chapter. We, therefore, direct the reader to ref. ${ }^{[241]}$ and instead, focus here on the less studied metal-ion conductors that are gaining more prominence with the emergence of alternative and higher-valent battery technologies.

The most critical cations in this context are $\mathrm{Li}^{+}, \mathrm{Na}^{+}, \mathrm{Mg}^{2+}, \mathrm{Zn}^{2+}$, and $\mathrm{Al}^{3+}$. The higher-valent cations $\mathrm{Mg}^{2+}$ and $\mathrm{Al}^{3+}$ are particularly attractive because fully functional electrolytes for these ions are still lacking: all liquid electrolytes run into limitations due to the electrode-electrolyte interface layers, and only very few solidstate electrolytes for multivalent ions reach ionic conductivity values close to the practically useful target of $10^{-3} \mathrm{~S} \mathrm{~cm}^{-1}$.[262] Owing to their generally low electronic conductivity, and their porous structures that can potentially offer conduits for ion transport, MOFs are gaining traction as a design platform for new solid-state electrolytes, especially for multi-valent ions. Below, we discuss the key characteristics that influence metal ion conductivity in MOFs.

\subsubsection{Pore size}

When considering solid-state electrolytes, one commonly searches for structures with continuous one- or two-dimensional channels that permit ion diffusion, as observed, for instance, in $\beta$ alumina, a classic $\mathrm{Na}^{+}$ion conductor. ${ }^{[263]}$ This line of thinking was extended to MOFs with sufficiently large pores to either $(I)$ promote direct diffusion of solvated metal ions, ${ }^{[264]}$ or (ii) host a liquid electrolyte that itself facilitates ionic transport within the pores $^{[265]}$. Both approaches produce ionically conducting compounds that present morphologically as solids and can thus be classified as solid electrolytes. Conductivity values exceeding $10^{-4} \mathrm{~S} \mathrm{~cm}^{-1}$ have been achieved for both monovalent and divalent metals. MOFs that allow direct transport of solvated ions can lead to electrolytes with high metal cation transference numbers (the measure of how much of the current is carried by the metal cation $v s$. the anion) - often higher than those shown by conventional liquid electrolytes. Conversely, although the second approach does not necessarily bring similar improvements in transport properties, it allows sampling of already proven liquid electrolytes while retaining the safety and construction benefits of a solid-state material.

Although a physical conduit or a minimal void is required for ion transport in either approach, it is more difficult to ascertain how important pore size or surface area truly are for ion conductivity, or indeed, at what point a pore is too large to be useful for this purpose. For instance, when impregnated with identical ionic liquids, ZIF-8 (pore aperture $=3.4 \AA$ ),${ }^{[266]}$ MOF-525-Cu (narrowest pore aperture $=7 \AA$ ) ${ }^{[267]}$ and UiO-66 (pore aperture $\left.=30 \AA\right)^{[268]}$ showed little difference in ionic conductivity, all in the range $10^{-4}$ $-10^{-5} \mathrm{~S} \mathrm{~cm}^{-1}$, or transference numbers, all ranging from 0.3 to 0.4 . However, pore size clearly influences $\mathrm{Mg}^{2+}$ ion conductivity in MOF-74 analogs, ${ }^{[245]}$ which increases nearly 100 -fold in moving from the smaller-pore $\mathrm{Mg}_{2}$ (DOBDC) (pore aperture $\sim 13 \AA$ ) to the larger-pore $\quad \mathrm{Mg}_{2}$ (DOBPDC) $\left(\mathrm{H}_{4} \mathrm{DOBPDC}=4,4^{\prime}\right.$ dihydroxybiphenyl-3,3'-dicarboxylic acid; pore aperture $\sim 21 \AA$ ). Increasing the pore size through isoreticular expansion, in this case, is assumed to allow a greater loading of $\mathrm{Mg}^{2+}$ salt within the pores. There is much to be learned about metal ion conductivity in MOFs, and although evidence points to pore size playing an important role in this context, more systematic studies are needed to determine optimal pore aperture for a given metal ion.

\subsubsection{Secondary building unit}

One of the more exciting developments in the chemistry of ionically conductive MOFs has been the improvement in the metal ion uptake and transference number through host-guest interactions. This is generally done by harnessing uncoordinated metal sites originally taken up by easily removable solvent molecules. These under-coordinated SBU sites bind anions, which leaves 'free' metal cations inside the pores. Anion binding further serves as a driving force for improved electrolyte loading and makes cations the majority charge carriers, leading to high conductivities and transference numbers exceeding 0.5 (compared to 0.3-0.4 usually seen for liquid electrolytes). [269]

This strategy was first implemented in $\mathrm{Mg}_{2}$ (DOBDC), where incorporation of $\mathrm{Li}(\mathrm{O} \mathrm{Pr})$ produced a material with a conductivity of $3.1 \times 10^{-4} \mathrm{~S} \mathrm{~cm}^{-1}$, approximately one hundred times higher than that of the same MOF soaked in $\mathrm{LiBF}_{4} \cdot{ }^{[269]}$ The authors propose that the improvement is due to isopropoxide binding to unsaturated $\mathrm{Mg}^{2+}$ sites, which drives higher loading of $\mathrm{Li}^{+}$ compared to the poorly coordinating $\mathrm{BF}_{4}^{-}$species. A similar strategy of anion binding, leading to increased $\mathrm{Li}^{+}$or $\mathrm{Mg}^{2+}$ loading, was adopted with $\mathrm{Cu}_{4}(\mathrm{ttpm})_{2} \quad\left(\mathrm{H}_{4}\right.$ ttpm $=$ tetrakis $(4-$ tetrazolylphenyl)methane). ${ }^{[264]}$ Here, the strategy also led to materials with high ionic conductivities reaching $1 \times 10^{-4} \mathrm{~S} \mathrm{~cm}^{-1}$.

\subsubsection{Framework charge}

The MOFs discussed so far are charge-neutral, with no chargebalancing ions residing in the pores. Mobile metal ions are introduced post-synthetically as components of simple salts. This approach is powerful because it allows sampling of a large library of known materials: the vast majority of MOFs are neutral. The significant downside is that anions in the metal salts introduced post-synthetically are often also mobile. Indeed, even when anions are bound to coordinatively unsaturated SBUs, as discussed above, they retain considerable mobility, and metal ion transference numbers rarely exceed 0.6 . A promising solution to increasing cation transference numbers is the use of anionic frameworks, which comprise overall negatively charged frameworks that naturally require cations for charge balance. The cations are not connected to the frameworks and are thus residing in the open pores. Using anionic MOFs as solid electrolytes indeed allows for considerably higher metal transference numbers approaching 0.9 for $\mathrm{Li}^{+}$. A particularly successful example of this approach is MOF-688, ${ }^{[247]}$ a material made from Anderson-type polyoxometalates (POM) and tetrakis(4formyphenyl)methane. In the parent MOF, the anionic POM units 
are balanced by tetrabutylammonium cations. The latter are readily replaced by metathesis with $\mathrm{Li}^{+}$to yield a material with a conductivity of $3.4 \times 10^{-4} \mathrm{~S} \mathrm{~cm}^{-1}$ at $20{ }^{\circ} \mathrm{C}$, and an impressive $\mathrm{Li}^{+}$ transference number of 0.87 .

Although salt metathesis is not within the purview of reticular chemistry, when applied to reticular materials it can lead to systematic studies of ion transport. With MOFs and metal ions, these studies are still nascent but impressive results for absolute conductivity values and selective cation transport with high transference numbers, especially for higher-valent metals, portend an increasing importance for MOFs and reticular chemistry in the design of solid electrolytes.

Above, we discussed the features we believe to be key for understanding the current conductive MOF literature. Both electronic and metal-ion conductors ultimately share the same goal - to conduct electrical current. Despite this commonality, their structures and properties are often strikingly different. It is this structural and functional variety as well as the degree of control over them, which is the key-strength of MOFs, and reticular materials in general.

\section{Conclusions}

Decades of fundamental research on reticular chemistry has afforded versatile MOF and COF structures and enabled a detailed understanding of their properties. This has paved the way for a paradigm shift from fundamental science toward applied research. In this review, we have aimed to inspire scientists by spotlighting the significant progress that has been achieved in the various fields of reticular research so far. An essential starting point for developing reticular material applications is defining current outstanding challenges of societal relevance. Being driven by the aspiration of implementing COFs and MOFs into practical devices, we would like to give some recommendation concerning important aspects in the pursuit of industrial applications:

1. One major technical hurdle that has to be overcome is processing and formulation. It is essential to find state-ofthe-art solutions for shaping and structuring of these materials into the optimal macroscopic forms required for specific applications.

2. Another essential point is expanding investigations from purely fundamental to more practical characteristics such as mechanical, chemical, and long-term ambient stability to obtain a deeper insight into the operational range of MOFs and COFs.

3. Significant efforts should be devoted into developing of effective synthesis methods to obtain products at high yields and with no side products, as well as efficient activation protocols to minimize material loss after processing, and in turn, increase the STY.

4. To meet industrial needs, large-scale sustainable manufacturing that is simultaneously economical, ecological and safe has to be targeted, as well. Specifically, green synthesis conditions and inexpensive chemicals should be employed and recyclability issue should be taken into account.

5. Safety regulation standards of various countries are important points to be aware of during commercialization. For instance, some metals such as $\mathrm{Cr}, \mathrm{Mn}, \mathrm{Ni}$ or solvent such as $N, N$-dimethylformamide, $N$-methyl-2-pyrrolidone are restricted in some countries.

6. After all these steps, a business model should be developed, and the following issues are worth considering: How big is the market for the product? Does it resolve an unsolved problem or provide significant benefits compared to current products? Is this technology feasible and patentable? How profitable would the technology be?

7. Finally, after impartial pondering over all the risks involved in commercializing MOFs and COFs and considering all the pros and cons, one might make a start-up company and truly transform the scientific extravagancies into widely applied products.

While the past decades have seen significant progress in the chemistry and applications of MOFs and COFs, there still remains a vast space for exploration, particularly in the context of commercialization. With respect to the emerging field of COFs, more efforts need to be devoted to fundamental research into their properties to make full use of their potential in applied research. In contrast, making use of the vast body of basic research on MOFs, identifying and optimizing materials for specific applications and moving reticular materials from the lab toward industrial applications is paramount.

\section{Acknowledgements}

G.A. thanks the Research Foundation-Flanders (FWO) for the fellowship 1SA7320N and acknowledges Víctor Rubio-Giménez for the discussion on the conductivity of 2D MOFs.

Keywords: MOFs $\cdot$ COFs $\cdot$ reticular chemistry $\cdot$ industrial applications $\cdot$ commercialization

\section{References}

[1] D. Ongari, L. Talirz, B. Smit, ACS Cent. Sci. 2020, 6, 1890-1900.

[2] C. Gropp, S. Canossa, S. Wuttke, F. Gándara, Q. Li, O. M. Yaghi, 2020, 6, 1255-1273.

[3] H. Reinsch, Eur. J. Inorg. Chem. 2016, 2016, 4290-4299.

[4] Z. Chen, M. C. Wasson, R. J. Drout, L. Robison, K. B. Idrees, J. G. Knapp, F. A. Son, X. Zhang, W. Hierse, C. Kühn, S. Marx, B. Hernandez, O. K. Farha, Faraday Discuss. 2020, 1-89.

[5] F. Haase, P. Hirschle, R. Freund, S. Furukawa, Z. Ji, S. Wuttke, Angew. Chemie - Int. Ed. 2020, 59, 22350-22370.

[6] J. Ren, X. Dyosiba, N. M. Musyoka, H. W. Langmi, M. Mathe, S Liao, Coord. Chem. Rev. 2017, 352, 187-219.

[7] Nat. Chem. 2016, 8, 987.

[8] I. Tibbetts, G. E. Kostakis, Molecules 2020, 25, 1-32.

[9] W. Xu, O. M. Yaghi, ACS Cent. Sci. 2020, 6, 1348-1354.

[10] I. M. Hönicke, I. Senkovska, V. Bon, I. A. Baburin, N. Bönisch, S. Raschke, J. D. Evans, S. Kaskel, Angew. Chemie - Int. Ed. 2018, 57, 13780-13783.

[11] T. Segakweng, N. M. Musyoka, J. Ren, P. Crouse, H. W. Langmi, Res. Chem. Intermed. 2016, 42, 4951-4961.

[12] L. Wang, L. Wang, J. Zhao, T. Yan, J. Appl. Phys. 2012, 111, 1-7.

[13] L. Zhu, Y. B. Zhang, Molecules 2017, 22, 1149.

[14] H. Deng, S. Grunder, K. E. Cordova, C. Valente, H. Furukawa, M. 
Hmadeh, F. Gándara, A. C. Whalley, Z. Liu, S. Asahina, H. Kazumori, M. O’Keeffe, O. Terasaki, J. F. Stoddart, O. M. Yaghi, Science 2012, 336, 1018-1023.

[15] L. Zhang, S. Jee, J. Park, M. Jung, D. Wallacher, A. Franz, W. Lee, M. Yoon, K. Choi, M. Hirscher, H. Oh, J. Am. Chem. Soc. 2020, 141, 19850-19858.

[16] H. Li, J. Ding, X. Guan, F. Chen, C. Li, L. Zhu, M. Xue, D. Yuan, V. Valtchev, Y. Yan, S. Qiu, Q. Fang, J. Am. Chem. Soc. 2020, 142, 13334-13338.

[17] Y. Li, Q. Wu, X. Guo, M. Zhang, B. Chen, G. Wei, X. Li, X. Li, S. Li, L. Ma, Nat. Commun. 2020, 11, 1-9.

[18] H. Furukawa, Y. B. Go, N. Ko, Y. K. Park, F. J. Uribe-Romo, J. Kim, M. O’Keeffe, O. M. Yaghi, Inorg. Chem. 2011, 50, 9147-9152.

[19] V. Colombo, S. Galli, H. J. Choi, G. D. Han, A. Maspero, G. Palmisano, N. Masciocchi, J. R. Long, Chem. Sci. 2011, 2, 13111319.

[20] X. Guan, H. Li, Y. Ma, M. Xue, Q. Fang, Y. Yan, V. Valtchev, S. Qiu Nat. Chem. 2019, 11, 587-594.

[21] K. A. Cychosz, A. J. Matzger, Langmuir 2010, 26, 17198-17202.

[22] D. Banerjee, S. J. Kim, J. B. Parise, Cryst. Growth Des. 2009, 9 , 2500-2503.

[23] N. W. Ockwig, A. P. Co, M. O. Keeffe, A. J. Matzger, O. M. Yaghi, 2005, 310, 1166-1171.

[24] K. Yang, G. Zhou, Q. Xu, RSC Adv. 2016, 6, 37506-37514.

[25] J. Sun, A. lakunkov, I. A. Baburin, B. Joseph, V. Palermo, A. V. Talyzin, Angew. Chemie - Int. Ed. 2020, 59, 1087-1092.

[26] J. H. Carter, C. G. Morris, H. G. W. Godfrey, S. J. Day, J. Potter, S. P. Thompson, C. C. Tang, S. Yang, M. Schröder, ACS Appl. Mater. Interfaces 2020, 12, 42949-42954.

E. Jin, J. Li, K. Geng, Q. Jiang, H. Xu, Q. Xu, D. Jiang, Nat Commun. 2018, 9, 1-10.

S. Mukhopadhyay, J. Debgupta, C. Singh, R. Sarkar, O. Basu, S. K. Das, ACS Appl. Mater. Interfaces 2019, 11, 13423-13432.

9] H. S. Sasmal, H. B. Aiyappa, S. N. Bhange, S. Karak, A. Halder, S Kurungot, R. Banerjee, Angew. Chemie 2018, 130, 11060-11064. T. Kambe, R. Sakamoto, T. Kusamoto, T. Pal, N. Fukui, K. Hoshiko, T. Shimojima, Z. Wang, T. Hirahara, K. Ishizaka, S. Hasegawa, F. Liu, H. Nishihara, J. Am. Chem. Soc. 2014, 136, 14357-14360. H. Li, J. Chang, S. Li, X. Guan, D. Li, C. Li, L. Tang, M. Xue, Y. Yan, V. Valtchev, S. Qiu, Q. Fang, J. Am. Chem. Soc. 2019, 141, 1332413329.

R. Dong, P. Han, H. Arora, M. Ballabio, M. Karakus, Z. Zhang, C. Shekhar, P. Adler, P. S. Petkov, A. Erbe, S. C. B. Mannsfeld, C. Felser, T. Heine, M. Bonn, X. Feng, E. Cánovas, Nat. Mater. 2018, 17, 1027-1032.

[33] S. Wan, F. Gándara, A. Asano, H. Furukawa, A. Saeki, S. K. Dey, L. Liao, M. W. Ambrogio, Y. Y. Botros, X. Duan, S. Seki, J. F. Stoddart, O. M. Yaghi, Chem. Mater. 2011, 23, 4094-4097.

[34] S. Wang, T. Kitao, N. Guillou, M. Wahiduzzaman, C. MartineauCorcos, F. Nouar, A. Tissot, L. Binet, N. Ramsahye, S. DevautourVinot, S. Kitagawa, S. Seki, Y. Tsutsui, V. Briois, N. Steunou, G. Maurin, T. Uemura, C. Serre, Nat. Commun. 2018, 9, 1-9. X. Ding, J. Guo, X. Feng, Y. Honsho, J. Guo, S. Seki, P. Maitarad, A. Saeki, S. Nagase, D. Jiang, Angew. Chemie - Int. Ed. 2011, 50, 1289-1293.

[36] H. Furukawa, N. Ko, Y. B. Go, N. Aratani, S. B. Choi, E. Choi, A. Ö. Yazaydin, R. Q. Snurr, M. O’Keeffe, J. Kim, O. M. Yaghi, Science
2010, 329, 424-428.

[37] H. Furukawa, O. M. Yaghi, J. Am. Chem. Soc. 2009, 131, 88758883.

[38] T. Tian, Z. Zeng, D. Vulpe, M. E. Casco, G. Divitini, P. A. Midgley, J. Silvestre-Albero, J. C. Tan, P. Z. Moghadam, D. Fairen-Jimenez, Nat. Mater. 2018, 17, 174-179.

[39] Z. Chen, P. Li, R. Anderson, X. Wang, X. Zhang, L. Robison, L. R. Redfern, S. Moribe, T. Islamoglu, D. A. Gómez-Gualdrón, T. Yildirim, J. F. Stoddart, O. K. Farha, Science 2020, 368, 297-303.

[40] N. Hanikel, M. S. Prévot, F. Fathieh, E. A. Kapustin, H. Lyu, H. Wang, N. J. Diercks, T. G. Glover, O. M. Yaghi, ACS Cent. Sci. 2019, 5, 1699-1706.

[41] H. L. Nguyen, N. Hanikel, S. J. Lyle, C. Zhu, D. M. Proserpio, O. M. Yaghi, J. Am. Chem. Soc. 2020, 142, 2218-2221.

[42] H. E. Emam, R. M. Abdelhameed, H. B. Ahmed, J. Environ. Chem. Eng. 2020, 8, 104386.

[43] H. Li, K. Wang, Y. Sun, C. T. Lollar, J. Li, H. C. Zhou, Mater. Today 2018, 21, 108-121.

[44] H. Furukawa, K. E. Cordova, M. O’Keeffe, O. M. Yaghi, Science 2013, 341, 1230444.

[45] H. Li, M. Eddaoudi, M. O'Keeffe, O. M. Yaghi, Nature 1999, 402, 276-279.

[46] Ü. Kökçam-Demir, A. Goldman, L. Esrafili, M. Gharib, A. Morsali, O. Weingart, C. Janiak, Chem. Soc. Rev. 2020, 49, 2751-2798.

[47] R. Matsuda, R. Kitaura, S. Kitagawa, Y. Kubota, R. V. Belosludov, T. C. Kobayashi, H. Sakamoto, T. Chiba, M. Takata, Y. Kawazoe, Y. Mita, Nature 2005, 436, 238-241.

[48] A. G. Wong-Foy, A. J. Matzger, O. M. Yaghi, J. Am. Chem. Soc 2006, 128, 3494-3495.

[49] H. Hayashi, A. P. Côté, H. Furukawa, M. O’Keeffe, O. M. Yaghi, Nat. Mater. 2007, 6, 501-506.

[50] Y. Khabzina, J. Dhainaut, M. Ahlhelm, H. J. Richter, H. Reinsch, N. Stock, D. Farrusseng, Ind. Eng. Chem. Res. 2018, 57, 8200-8208.

[51] M. T. Kapelewski, T. Runčevski, J. D. Tarver, H. Z. H. Jiang, K. E. Hurst, P. A. Parilla, A. Ayala, T. Gennett, S. A. Fitzgerald, C. M. Brown, J. R. Long, Chem. Mater. 2018, 30, 8179-8189.

[52] H. Li, L. Li, R.-B. Lin, W. Zhou, Z. Zhang, S. Xiang, B. Chen, EnergyChem 2019, 1, 100006.

[53] Y. He, F. Chen, B. Li, G. Qian, W. Zhou, B. Chen, Coord. Chem. Rev. 2018, 373, 167-198

[54] M. S. Dresselhaus, K. A. Williams, P. C. Eklund, MRS Bull. 1999, 24, 45-50.

[55] H. Yang, S. Orefuwa, A. Goudy, Microporous Mesoporous Mater. 2011, 143, 37-45.

[56] Y. Li, R. T. Yang, Langmuir 2007, 23, 12937-12944.

[57] T. Runčevski, M. T. Kapelewski, R. M. Torres-Gavosto, J. D. Tarver, C. M. Brown, J. R. Long, Chem. Commun. 2016, 52, 8251-8254.

[58] M. Dinča, A. Dailly, Y. Liu, C. M. Brown, D. A. Neumann, J. R. Long, J. Am. Chem. Soc. 2006, 128, 16876-16883.

[59] M. Dincă, W. S. Han, Y. Liu, A. Dailly, C. M. Brown, J. R. Long, Angew. Chemie - Int. Ed. 2007, 46, 1419-1422.

[60] J. L. Mendoza-Cortés, S. S. Han, W. A. Goddard, J. Phys. Chem. A 2012, 116, 1621-1631.

[61] Z. Ke, Y. Cheng, S. Yang, F. Li, L. Ding, Int. J. Hydrogen Energy 2017, 42, 11461-11468.

[62] E. Klontzas, E. Tylianakis, G. E. Froudakis, J. Phys. Chem. C 2009, 113, 21253-21257. 
[63] Z. Kang, Y. Peng, Y. Qian, D. Yuan, M. A. Addicoat, T. Heine, Z. Hu, L. Tee, Z. Guo, D. Zhao, Chem. Mater. 2016, 28, 1277-1285.

[64] B. P. Biswal, H. D. Chaudhari, R. Banerjee, U. K. Kharul, Chem. - A Eur. J. 2016, 22, 4695-4699.

[65] H. Fan, A. Mundstock, A. Feldhoff, A. Knebel, J. Gu, H. Meng, J. Caro, J. Am. Chem. Soc. 2018, 140, 10094-10098.

[66] S. Yuan, X. Li, J. Zhu, G. Zhang, P. Van Puyvelde, B. Van Der Bruggen, Chem. Soc. Rev. 2019, 48, 2665-2681.

[67] M. Kondo, T. Yoshitomi, K. Seki, H. Matsuzaka, S. Kitagawa, Angew. Chemie - Int. Ed. 1997, 36, 1725-1727.

[68] J. A. Mason, M. Veenstra, J. R. Long, Chem. Sci. 2014, 5, 32-51.

[69] D. Alezi, Y. Belmabkhout, M. Suyetin, P. M. Bhatt, L. J. Weseliński, V. Solovyeva, K. Adil, I. Spanopoulos, P. N. Trikalitis, A. H. Emwas, M. Eddaoudi, J. Am. Chem. Soc. 2015, 137, 13308-13318.

[70] Z. Hulvey, B. Vlaisavljevich, J. A. Mason, E. Tsivion, T. P. Dougherty, E. D. Bloch, M. Head-Gordon, B. Smit, J. R. Long, C. M. Brown, J. Am. Chem. Soc. 2015, 137, 10816-10825.

[71] D. Feng, K. Wang, Z. Wei, Y. P. Chen, C. M. Simon, R. K. Arvapally, R. L. Martin, M. Bosch, T. F. Liu, S. Fordham, D. Yuan, M. A. Omary, M. Haranczyk, B. Smit, H. C. Zhou, Nat. Commun. 2014, 5, 1-9.

[72] B. Li, H. M. Wen, H. Wang, H. Wu, M. Tyagi, T. Yildirim, W. Zhou, B. Chen, J. Am. Chem. Soc. 2014, 136, 6207-6210.

[73] Z. Hulvey, B. Vlaisavljevich, J. A. Mason, E. Tsivion, T. P. Dougherty, E. D. Bloch, M. Head-Gordon, B. Smit, J. R. Long, C. M. Brown, J. Am. Chem. Soc. 2015, 137, 10816-10825.

[74] J. A. Mason, J. Oktawiec, M. K. Taylor, M. R. Hudson, J. Rodriguez, J. E. Bachman, M. I. Gonzalez, A. Cervellino, A. Guagliardi, C. M. Brown, P. L. Llewellyn, N. Masciocchi, J. R. Long, Nature 2015, 527, 357-361.

[75] D. Tanaka, M. Higuchi, S. Horike, R. Matsuda, Y. Kinoshita, N. Yanai, S. Kitagawa, Chem. - An Asian J. 2008, 3, 1343-1349.

[76] S. Xiang, W. Zhou, J. M. Gallegos, Y. Liu, B. Chen, J. Am. Chem. Soc. 2009, 131, 12415-12419.

[77] S. Xiang, W. Zhou, Z. Zhang, M. A. Green, Y. Liu, B. Chen, Angew. Chemie - Int. Ed. 2010, 49, 4615-4618.

[78] X. Duan, Y. Cui, Y. Yang, G. Qian, CrystEngComm 2017, 19, 14641469.

[79] Z. Li, Y. Zhi, X. Feng, X. Ding, Y. Zou, X. Liu, Y. Mu, Chem. - A Eur. J. 2015, 21, 12079-12084.

[80] A. R. Millward, O. M. Yaghi, J. Am. Chem. Soc. 2005, 127, 1799817999.

[81] A. Ö. Yazaydin, R. Q. Snurr, T. H. Park, K. Koh, J. Liu, M. D. LeVan, A. I. Benin, P. Jakubczak, M. Lanuza, D. B. Galloway, J. J. Low, R. R. Willis, J. Am. Chem. Soc. 2009, 131, 18198-18199.

[82] D. Britt, H. Furukawa, B. Wang, T. G. Glover, O. M. Yaghi, Proc. Natl. Acad. Sci. U. S. A. 2009, 106, 20637-20640.

[83] C. R. Wade, M. Dincă, Dalt. Trans. 2012, 41, 7931-7938.

[84] C. Hon Lau, R. Babarao, M. R. Hill, Chem. Commun. 2013, 49, 3634-3636.

[85] J. Kim, S. T. Yang, S. B. Choi, J. Sim, J. Kim, W. S. Ahn, J. Mater. Chem. 2011, 21, 3070-3076.

[86] O. Shekhah, Y. Belmabkhout, Z. Chen, V. Guillerm, A. Cairns, K. Adil, M. Eddaoudi, Nat. Commun. 2014, 5, 1-7.

[87] P. Abdolalian, A. Morsali, Polyhedron 2019, 161, 56-62.

[88] J. Qian, J. Shen, Q. Li, Y. Hu, S. Huang, Cryst. Eng. Comm. 2017, $19,5346-5350$.
[89] G. Zhang, G. Wei, Z. Liu, S. R. J. Oliver, H. Fei, Chem. Mater. 2016, 28, 6276-6281.

[90] T. M. McDonald, W. R. Lee, J. A. Mason, B. M. Wiers, C. S. Hong, J. R. Long, J. Am. Chem. Soc. 2012, 134, 7056-7065.

[91] H. Deng, C. J. Doonan, H. Furukawa, R. B. Ferreira, J. Towne, C. B. Knobler, B. Wang, O. M. Yaghi, Science 2010, 846-851.

[92] H. Hayashi, A. P. Côté, H. Furukawa, M. O'Keeffe, O. M. Yaghi, Nat. Mater. 2007, 6, 501-506.

[93] M. Zeeshan, V. Nozari, M. B. Yagci, T. Islk, U. Unal, V. Ortalan, S. Keskin, A. Uzun, J. Am. Chem. Soc. 2018, 140, 10113-10116.

[94] K. J. Chen, Q. Y. Yang, S. Sen, D. G. Madden, A. Kumar, T. Pham, K. A. Forrest, N. Hosono, B. Space, S. Kitagawa, M. J. Zaworotko, Angew. Chemie - Int. Ed. 2018, 57, 3332-3336.

[95] D. A. Reed, B. K. Keitz, J. Oktawiec, J. A. Mason, T. Runcevski, D. J. Xiao, L. E. Darago, V. Crocellà, S. Bordiga, J. R. Long, Nature 2017, 550, 96-100

[96] G. L. Smith, J. E. Eyley, X. Han, X. Zhang, J. Li, N. M. Jacques, H. G. W. Godfrey, S. P. Argent, L. J. McCormick McPherson, S. J.

Teat, Y. Cheng, M. D. Frogley, G. Cinque, S. J. Day, C. C. Tang, T. L. Easun, S. Rudić, A. J. Ramirez-Cuesta, S. Yang, M. Schröder, Nat. Mater. 2019, 18, 1358-1365.

[97] S. Yang, J. Sun, A. J. Ramirez-Cuesta, S. K. Callear, W. I. F. David, D. P. Anderson, R. Newby, A. J. Blake, J. E. Parker, C. C. Tang, M. Schröder, Nat. Chem. 2012, 4, 887-894.

[98] J. Antonio Zárate, E. Sánchez-González, T. Jurado-Vázquez, A. Gutiérrez-Alejandre, E. González-Zamora, I. Castillo, G. Maurin, I. A. Ibarra, Chem. Commun. 2019, 55, 3049-3052.

[99] J. Liu, W. Xia, W. Mu, P. Li, Y. Zhao, R. Zou, J. Mater. Chem. A 2015, 3, 5275-5279.

[100] J. Li, X. Han, X. Zhang, A. M. Sheveleva, Y. Cheng, F. Tuna, E. J. L. McInnes, L. J. McCormick McPherson, S. J. Teat, L. L. Daemen, A. J. Ramirez-Cuesta, M. Schröder, S. Yang, Nat. Chem. 2019, 11, 1085-1090.

[101] C. J. Doonan, D. J. Tranchemontagne, T. G. Glover, J. R. Hunt, O. M. Yaghi, Nat. Chem. 2010, 2, 235-238.

[102] K. Kerkel, J. Arno, G. Reichl, J. Feicht, H. Winzig, O. K. Farha, W. Morris, P. W. Siu, G. M. Tom, M. H. Weston, P. E. Fuller, in Proc. Int. Conf. Ion Implant. Technol., 2018, 223-226.

[103] H. Li, M. Eddaoudi, M. O'Keeffe, O. M. Yaghi, Nature, 1999, 402, 276-279.

[104] T. Loiseau, C. Serre, C. Huguenard, G. Fink, F. Taulelle, M. Henry, T. Bataille, G. Férey, Chem. - A Eur. J. 2004, 10, 1373-1382.

[105] A. Henschel, I. Senkovska, S. Kaskel, Adsorption 2011, 17, 219226.

[106] H. Furukawa, F. Gándara, Y. B. Zhang, J. Jiang, W. L. Queen, M. R Hudson, O. M. Yaghi, J. Am. Chem. Soc. 2014, 136, 4369-4381.

[107] J. T. Hupp, K. R. Poeppelmeler, Science 2005, 309, 2008-2009.

[108] Y. Bai, Y. Dou, L. H. Xie, W. Rutledge, J. R. Li, H. C. Zhou, Chem. Soc. Rev. 2016, 45, 2327-2367.

[109] N. C. Burtch, H. Jasuja, K. S. Walton, Chem. Rev. 2014, 114, 10575-10612.

[110] C. S. Diercks, O. M. Yaghi, Science 2017, 355, 6328.

[111] A. Striolo, P. K. Naicker, A. A. Chialvo, P. T. Cummings, K. E. Gubbins, Adsorption 2005, 11, 397-401.

[112] S. K. Henninger, H. A. Habib, C. Janiak, J. Am. Chem. Soc. 2009 , 131, 2776-2777.

[113] J. Ehrenmann, S. K. Henninger, C. Janiak, Eur. J. Inorg. Chem. 
2011, 471-474.

[114] M. J. Kalmutzki, C. S. Diercks, O. M. Yaghi, Adv. Mater. 2018, 30 $1-26$.

[115] N. Ko, P. G. Choi, J. Hong, M. Yeo, S. Sung, K. E. Cordova, H. J. Park, J. K. Yang, J. Kim, J. Mater. Chem. A 2015, 3, 2057-2064.

[116] S. J. Ernst, M. Baumgartner, D. Fröhlich, H. J. Bart, S. K. Henninger, Chemie-Ingenieur-Technik 2017, 89, 1650-1660.

[117] H. Kummer, F. Jeremias, A. Warlo, G. Füldner, D. Fröhlich, C. Janiak, R. Gläser, S. K. Henninger, Ind. Eng. Chem. Res. 2017, 56, 8393-8398.

[118] S. Kim, Hyunho, Yang, S. R. Rao, S. Narayanan, E. A. Kapustin, H. Furukawa, A. S. Umans, O. M. Yaghi, E. N. Wang, Science 2017, 434, 430-434.

[119] A. J. Rieth, S. Yang, E. N. Wang, M. Dincă, ACS Cent. Sci. 2017, 3 , 668-672.

[120] F. Fathieh, M. J. Kalmutzki, E. A. Kapustin, P. J. Waller, J. Yang, O. M. Yaghi, Sci. Adv. 2018, 4, 1-10.

[121] M. W. Logan, S. Langevin, Z. Xia, Sci. Rep. 2020, 10, 1-11.

[122] A. Bavykina, N. Kolobov, I. S. Khan, J. A. Bau, A. Ramirez, J. Gascon, Chem. Rev. 2020, 120, 8468-8535.

[123] M. Fujita, S. Washizu, K. Ogura, Y. J. Kwon, J. Am. Chem. Soc. 1994, 116, 1151-1152

[124] R. Tannenbaum, Chem. Mater. 1994, 6, 550-555.

[125] T. Sawaki, Y. Aoyama, J. Am. Chem. Soc. 1999, 121, 4793-4798.

[126] T. Sawaki, T. Dewa, Y. Aoyama, J. Am. Chem. Soc. 1998, 120, 8539-8540.

[127] B. Gómez-Lor, E. Gutiérrez-Puebla, M. Iglesias, M. A. Monge, C Ruiz-Valero, N. Snejko, Chem. Mater. 2005, 17, 2568-2573.

[128] J. S. Seo, D. Whang, H. Lee, S. I. Jun, J. Oh, Y. J. Jeon, K. Kim Nature 2000, 404, 982-986.

[129] K. Schlichte, T. Kratzke, S. Kaskel, Microporous Mesoporous Mater 2004, 73, 81-88.

[130] S. Hermes, M. K. Schröter, R. Schmid, L. Khodeir, M. Muhler, A. Tissler, R. W. Fischer, R. A. Fischer, Angew. Chemie - Int. Ed. 2005, 44, 6237-6241.

[131] Y. M. A. Yamada, Y. Maeda, Y. Uozumi, Org. Lett. 2006, 8, 42594262.

[132] M. Dan-Hardi, C. Serre, T. Frot, L. Rozes, G. Maurin, C. Sanchez, G. Férey, J. Am. Chem. Soc. 2009, 131, 10857-10859.

[133] V. P. Santos, T. A. Wezendonk, J. J. D. Jaén, A. I. Dugulan, M. A Nasalevich, H. U. Islam, A. Chojecki, S. Sartipi, X. Sun, A. A. Hakeem, A. C. J. Koeken, M. Ruitenbeek, T. Davidian, G. R. Meima, G. Sankar, F. Kapteijn, M. Makkee, J. Gascon, Nat. Commun. 2015, 6, 1-8.

[134] K. C. Szeto, C. Prestipino, C. Lamberti, A. Zecchina, S. Bordiga, M. Bjørgen, M. Tilset, K. F. Lillerud, Chem. Mater. 2007, 19, 211-220.

[135] K. C. Szeto, K. P. Lillerud, M. Tilset, M. Bjørgen, C. Prestipino, A. Zecchina, C. Lamberti, S. Bordiga, J. Phys. Chem. B 2006, 110, 21509-21520.

[136] L. Alaerts, E. Séguin, H. Poelman, F. Thibault-Starzyk, P. A. Jacobs, D. E. De Vos, Chem. - A Eur. J. 2006, 12, 7353-7363.

[137] Y. K. Hwang, D. Y. Hong, J. S. Chang, S. H. Jhung, Y. K. Seo, J. Kim, A. Vimont, M. Daturi, C. Serre, G. Férey, Angew. Chemie - Int. Ed. 2008, 47, 4144-4148.

[138] A. Hu, H. L. Ngo, W. Lin, Angew. Chemie - Int. Ed. 2003, 42, 6000 6003.

[139] A. Hu, H. L. Ngo, W. Lin, J. Am. Chem. Soc. 2003, 125, 11490-
11491.

[140] C. De Wu, A. Hu, L. Zhang, W. Lin, J. Am. Chem. Soc. 2005, 127 8940-8941.

[141] A. M. Rasero-Almansa, M. Iglesias, F. Sánchez, RSC Adv. 2016, 6, 106790-106797.

[142] M. Giménez-Marqués, A. Santiago-Portillo, S. Navalón, M. Álvaro, V. Briois, F. Nouar, H. Garcia, C. Serre, J. Mater. Chem. A 2019, 7, 20285-20292.

[143] C. Wang, Z. Xie, K. E. Dekrafft, W. Lin, J. Am. Chem. Soc. 2011, 133, 13445-13454.

[144] D. Y. Osadchii, A. I. Olivos-Suarez, Á. Szécsényi, G. Li, M. A. Nasalevich, I. A. Dugulan, P. S. Crespo, E. J. M. Hensen, S. L. Veber, M. V. Fedin, G. Sankar, E. A. Pidko, J. Gascon, ACS Catal. 2018, 8, 5542-5548.

[145] F. Schröder, D. Esken, M. Cokoja, M. van den Berg, J. Am. Chem. Soc. 2008, 6119-6130.

[146] A. Henschel, K. Gedrich, R. Kraehnert, S. Kaskel, Chem. Commun. 2008, 4192-4194.

[147] M. H. Alkordi, Y. Liu, R. W. Larsen, J. F. Eubank, M. Eddaoudi, J. Am. Chem. Soc. 2008, 130, 12639-12641.

[148] F. Lyu, Y. Zhang, R. N. Zare, J. Ge, Z. Liu, Nano Lett. 2014, 14, 5761-5765.

[149] V. Lykourinou, Y. Chen, X. Sen Wang, L. Meng, T. Hoang, L. J. Ming, R. L. Musselman, S. Ma, J. Am. Chem. Soc. 2011, 133, 10382-10385.

[150] R. J. Drout, L. Robison, O. K. Farha, Coord. Chem. Rev. 2019, 381, 151-160.

[151] J. Hwang, A. Ejsmont, R. Freund, J. Goscianska, B. V. K. J. Schmidt, S. Wuttke, Chem. Soc. Rev. 2020, 49, 3348-3422.

[152] L. Oar-Arteta, T. Wezendonk, X. Sun, F. Kapteijn, J. Gascon, Nanotechnol. Catal. 2017, 225-250.

[153] X. Sun, A. I. O. Suarez, M. Meijerink, T. Van Deelen, S. Ould-Chikh, J. Zečević, K. P. De Jong, F. Kapteijn, J. Gascon, Nat. Commun. 2017, 8, 1680 .

[154] H. Y. Lin, X. L. Wang, H. L. Hu, B. K. Chen, G. C. Liu, Solid State Sci. 2009, 11, 643-650.

[155] Z. T. Yu, Z. L. Liao, Y. S. Jiang, G. H. Li, G. D. Li, J. S. Chen, Chem. Commun. 2004, 1814-1815.

[156] S. Beg, M. Rahman, A. Jain, S. Saini, P. Midoux, C. Pichon, F. J. Ahmad, S. Akhter, Drug Discov. Today 2017, 22, 625-637.

[157] M. Peller, K. Böll, A. Zimpel, S. Wuttke, Inorg. Chem. Front. 2018, 5, 1760-1779.

[158] J. Della Rocca, W. Lin, Eur. J. Inorg. Chem. 2010, 3725-3734.

[159] W. J. Rieter, K. M. Pott, K. M. L. Taylor, W. Lin, J. Am. Chem. Soc. 2008, 130, 11584-11585.

[160] P. Horcajada, T. Chalati, C. Serre, B. Gillet, C. Sebrie, T. Baati, J. F. Eubank, D. Heurtaux, P. Clayette, C. Kreuz, J. S. Chang, Y. K. Hwang, V. Marsaud, P. N. Bories, L. Cynober, S. Gil, G. Férey, P. Couvreur, R. Gref, Nat. Mater. 2010, 9, 172-178.

[161] K. Lu, C. He, W. Lin, J. Am. Chem. Soc. 2014, 136, 16712-16715.

[162] K. Liang, R. Ricco, C. M. Doherty, M. J. Styles, S. Bell, N. Kirby, S. Mudie, D. Haylock, A. J. Hill, C. J. Doonan, P. Falcaro, Nat. Commun. 2015, 6, 1-8.

[163] J. Liu, Y. Yang, W. Zhu, X. Yi, Z. Dong, X. Xu, M. Chen, K. Yang, G. Lu, L. Jiang, Z. Liu, Biomaterials 2016, 97, 1-9.

[164] D. Chen, D. Yang, C. A. Dougherty, W. Lu, H. Wu, X. He, T. Cai, M. E. Van Dort, B. D. Ross, H. Hong, ACS Nano 2017, 11, 4315-4327. 
[165] T. Simon-Yarza, M. Giménez-Marqués, R. Mrimi, A. Mielcarek, R. Gref, P. Horcajada, C. Serre, P. Couvreur, Angew. Chemie - Int. Ed. 2017, 56, 15565-15569.

[166] W. J. Rieter, K. M. L. Taylor, H. An, W. Lin, W. Lin, J. Am. Chem. Soc. 2006, 128, 9024-9025.

[167] J. Della Rocca, D. Liu, W. Lin, Acc. Chem. Res. 2011, 44, 957-968.

[168] A. Zimpel, T. Preiß, R. Röder, H. Engelke, M. Ingrisch, M. Peller, J. O. Rädler, E. Wagner, T. Bein, U. Lächelt, S. Wuttke, Chem. Mater. 2016, 28, 3318-3326.

[169] K. Böll, A. Zimpel, O. Dietrich, S. Wuttke, M. Peller, Adv. Ther. 2020, 3, 1900126.

[170] K. E. Dekrafft, Z. Xie, G. Cao, S. Tran, M. Liqing, O. Z. Zhou, W. Lin, Angew. Chemie - Int. Ed. 2009, 48, 9901-9904.

[171] K. E. Dekrafft, W. S. Boyle, L. M. Burk, O. Z. Zhou, W. Lin, J. Mater. Chem. 2012, 22, 18139-18144.

[172] M. Lismont, L. Dreesen, S. Wuttke, Adv. Funct. Mater. 2017, 27, 116.

[173] K. Lu, C. He, W. Lin, J. Am. Chem. Soc. 2015, 137, 7600-7603.

[174] J. Park, D. Feng, S. Yuan, H. C. Zhou, Angew. Chemie - Int. Ed. 2015, 54, 430-435.

[175] J. Park, Q. Jiang, D. Feng, L. Mao, H. C. Zhou, J. Am. Chem. Soc. 2016, 138, 3518-3525.

[176] J. Liu, G. Yang, W. Zhu, Z. Dong, Y. Yang, Y. Chao, Z. Liu, Biomaterials 2017, 146, 40-48.

[177] P. Horcajada, C. Serre, M. Vallet-Regí, M. Sebban, F. Taulelle, G. Férey, Angew. Chemie - Int. Ed. 2006, 45, 5974-5978.

[178] T. T. Chen, J. T. Yi, Y. Y. Zhao, X. Chu, J. Am. Chem. Soc. 2018, 140, 9912-9920.

[179] X. Wu, H. Yue, Y. Zhang, X. Gao, X. Li, L. Wang, Y. Cao, M. Hou, H. An, L. Zhang, S. Li, J. Ma, H. Lin, Y. Fu, H. Gu, W. Lou, W. Wei, R. N. Zare, J. Ge, Nat. Commun. 2019, 10, 1-8.

[180] A. Poddar, J. J. Conesa, K. Liang, S. Dhakal, P. Reineck, G. Bryant, E. Pereiro, R. Ricco, H. Amenitsch, C. Doonan, X. Mulet, C. M. Doherty, P. Falcaro, R. Shukla, Small 2019, 15, 1-7.

[181] H. Wang, Y. Chen, H. Wang, X. Liu, X. Zhou, F. Wang, Angew. Chemie - Int. Ed. 2019, 58, 7380-7384.

[182] J. Zhuang, H. Gong, J. Zhou, Q. Zhang, W. Gao, R. H. Fang, L. Zhang, Sci. Adv. 2020, 6, 13.

[183] S. K. Alsaiari, S. Patil, M. Alyami, K. O. Alamoudi, F. A. Aleisa, J. S. Merzaban, M. Li, N. M. Khashab, J. Am. Chem. Soc. 2018, 140, 143-146.

[184] W. Zhu, J. Guo, J. O. Agola, J. G. Croissant, Z. Wang, J. Shang, E. Coker, B. Motevalli, A. Zimpel, S. Wuttke, C. J. Brinker, J. Am. Chem. Soc. 2019, 141, 7789-7796.

[185] W. Zhu, J. Guo, S. Amini, Y. Ju, J. O. Agola, A. Zimpel, J. Shang, A Noureddine, F. Caruso, S. Wuttke, J. G. Croissant, C. J. Brinker, Adv. Mater. 2019, 31, 1-9.

[186] R. Freund, U. Lächelt, T. Gruber, B. Rühle, S. Wuttke, ACS Nano 2018, 12, 2094-2105.

[187] O. M. Yaghi, G. Li, H. Li, Nature 1995, 378, 703-706.

[188] O. M. Yaghi, C. E. Davis, G. Li, H. Li, J. Am. Chem. Soc. 1997, 119 2861-2868.

[189] M. D. Allendorf, R. J. T. Houk, L. Andruszkiewicz, A. A. Talin, J. Pikarsky, A. Choudhury, K. A. Gall, P. J. Hesketh, J. Am. Chem. Soc. 2008, 130, 14404-14405.

[190] S. Achmann, G. Hagen, J. Kita, I. M. Malkowsky, C. Kiener, R. Moos, Sensors 2009, 9, 1574-1589.
[191] Y. Takashima, V. M. Martínez, S. Furukawa, M. Kondo, S. Shimomura, H. Uehara, M. Nakahama, K. Sugimoto, S. Kitagawa, Nat. Commun. 2011, 2, 168.

[192] M. G. Campbell, D. Sheberla, S. F. Liu, T. M. Swager, M. Dincă, Angew. Chemie Int. Ed. 2015, 54, 4349-4352.

[193] M. G. Campbell, S. F. Liu, T. M. Swager, M. Dincə, J. Am. Chem. Soc. 2015, 137, 13780-13783.

[194] M. R. Venkatesh, S. Sachdeva, B. El Mansouri, J. Wei, A. Bossche, D. Bosma, L. C. P. M. de Smet, E. J. R. Sudhölter, G. Q. Zhang, Sensors 2019, 19,1-19.

[195] H. Yuan, J. Tao, N. Li, A. Karmakar, C. Tang, H. Cai, S. J. Pennycook, N. Singh, D. Zhao, Angew. Chemie Int. Ed. 2019, 58, 14089-14094.

[196] Y. Wang, D. Liu, J. Yin, Y. Shang, J. Du, Z. Kang, R. Wang, Y. Chen, D. Sun, J. Jiang, Chem. Commun. 2020, 56, 703-706.

[197] S. S. Y. Chui, S. M. F. Lo, J. P. H. Charmant, A. G. Orpen, I. D. Williams, Science 1999, 283, 1148-1150.

[198] S.-I. Ohira, Y. Miki, T. Matsuzaki, N. Nakamura, Y. Sato, Y. Hirose, K. Toda, Anal. Chim. Acta 2015, 886, 188-193.

[199] A. Demessence, P. Horcajada, C. Serre, D. Grosso, Chem. Commun. 2009, 101, 7149-7151.

[200] G. Lu, J. T. Hupp, J. Am. Chem. Soc. 2010, 132, 7832-7833.

[201] F. M. Hinterholzinger, A. Ranft, J. M. Feckl, B. Rühle, T. Bein, B. V. Lotsch, J. Mater. Chem. 2012, 22, 10356-10362.

[202] R. C. Bailey, J. T. Hupp, J. Am. Chem. Soc. 2002, 124, 6767-6774.

[203] M. Tu, B. Xia, D. E. Kravchenko, M. L. Tietze, A. J. Cruz, I. Stassen, T. Hauffman, J. Teyssandier, S. De Feyter, Z. Wang, R. A. Fischer, B. Marmiroli, H. Amenitsch, A. Torvisco, M. de J. VelásquezHernández, P. Falcaro, R. Ameloot, Nat. Mater. 2020, 20, 93-99. [204] J. Tao, X. Wang, T. Sun, H. Cai, Y. Wang, T. Lin, D. Fu, L. L. Y. Ting, Y. Gu, D. Zhao, Sci. Rep. 2017, 7, 1-8.

[205] Y. Yan, T. Bein, J. Phys. Chem. 1992, 96, 9387-9393.

[206] S. Yamamoto, T. Carr, P. Wilkinson, "Matrix Sensors, Inc.," can be found under https://matrixsensorsinc.com/, 2016

[207] A. L. Robinson, V. Stavila, T. R. Zeitler, M. I. White, S. M. Thornberg, J. A. Greathouse, M. D. Allendorf, Anal. Chem. 2012, 84, 7043-7051.

[208] E.-X. Chen, H. Yang, J. Zhang, Inorg. Chem. 2014, 53, 5411-5413.

[209] N. Sharma, N. Sharma, P. Srinivasan, S. Kumar, J. Bosco, B. Rayappan, K. Kailasam, J. Mater. Chem. A 2018, 6, 18389-18395.

[210] J. Dou, M. Q. Arguilla, Y. Luo, J. Li, W. Zhang, L. Sun, J. L. Mancuso, L. Yang, T. Chen, L. R. Parent, G. Skorupskii, N. J. Libretto, C. Sun, M. C. Yang, P. V. Dip, E. J. Brignole, J. T. Miller, J. Kong, C. H. Hendon, J. Sun, M. Dincă, Nat. Mater. 2020, 20, 222228.

[211] N. A. Travlou, K. Singh, E. Rodríguez-Castellón, T. J. Bandosz, J. Mater. Chem. A 2015, 3, 11417-11429.

[212] M. S. Yao, W. X. Tang, G. E. Wang, B. Nath, G. Xu, Adv. Mater 2016, 28, 5229-5234.

[213] M. Leidinger, M. Rieger, T. Sauerwald, C. Alépée, A. Schütze, Sensors Actuators B. Chem. 2016, 236, 988-996.

[214] C. Zhang, M. Wang, L. Liu, X. Yang, X. Xu, Electrochem. commun. 2013, 33, 131-134

[215] W. Ling, G. Liew, Y. Li, Y. Hao, H. Pan, H. Wang, B. Ning, H. Xu, X. Huang, Adv. Mater. 2018, 30, 1-9.

[216] L. Mendecki, K. A. Mirica, Appl. Mater. Interfaces 2018, 10, 1924819257. 
[217] V. Chernikova, O. Yassine, O. Shekhah, M. Eddaoudi, K. N Salama, J. Mater. Chem. A 2018, 6, 5550-5554.

[218] H. Singh, V. K. Tomer, N. Jena, I. Bala, N. Sharma, D. Nepak, A. De Sarkar, K. Kailasam, S. K. Pal, J. Mater. Chem. A 2017, 5, 21820 21827.

[219] K. N. Chappanda, M. R. Tchalala, O. Shekhah, S. G. Surya, M. Eddaoudi, K. N. Salama, Sensors 2018, 18, 3898.

[220] R. Pohle, A. Tawil, P. Davydovskaya, M. Fleischer, Procedia Eng. 2011, 25, 108-111.

[221] D. W. Gardner, X. Gao, H. M. Fahad, A. T. Yang, S. He, A. Javey, C. Carraro, R. Maboudian, Chem. - A Eur. J. 2019, 25, 1317613183.

[222] S. Yuvaraja, S. G. Surya, V. Chernikova, M. T. Vijjapu, O. Shekhah, P. M. Bhatt, S. Chandra, M. Eddaoudi, K. N. Salama, ACS Appl. Mater. Interfaces 2020, 12, 18748-18760.

[223] A. Cadiau, N. Heymans, G. De Weireld, G. Maurin, K. N. Salama, Nat. Commun. 2019, 1-10.

[224] T. Lee, Z. X. Liu, H. L. Lee, Cryst. Growth Des. 2011, 11, 41464154.

[225] M. G. Campbell, S. F. Liu, T. M. Swager, M. Dincə, J. Am. Chem. Soc. 2015, 137, 13780-13783.

[226] S. Okur, Z. Zhang, M. Sarheed, P. Nick, U. Lemmer, L. Heinke, Sensors Actuators, B Chem. 2020, 306, 127502.

[227] J. A. Gustafson, C. E. Wilmer, J. Phys. Chem. C 2017, 121, 60336038.

[228] R. A. Potyrailo, Chem. Rev. 2016, 116, 11877-11923.

[229] S. R. Wang, J. Jiang, Chem. Commun. 2020, 56, 703-706.

[230] M. D. Allendorf, R. Dong, X. Feng, S. Kaskel, D. Matoga, V. Stavila, Chem. Rev. 2020, 120, 8581-8640.

[231] R. Zhao, Z. Liang, R. Zou, Q. Xu, Joule 2018, 2, 2235-2259.

[232] A. E. Baumann, D. A. Burns, B. Liu, V. S. Thoi, Commun. Chem. 2019, 2, 86.

[233] H. Wang, Q. L. Zhu, R. Zou, Q. Xu, Chem 2017, 2, 52-80.

[234] C. A. Downes, S. C. Marinescu, ChemSusChem 2017, 10, 43744392.

[235] M. G. Campbell, M. Dincă, Sensors 2017, 17, 1108.

[236] M. Ko, L. Mendecki, K. A. Mirica, Chem. Commun. 2018, 54, 78737891.

[237] I. Stassen, N. Burtch, A. Talin, P. Falcaro, M. Allendorf, R. Ameloot, Chem. Soc. Rev. 2017, 46, 3185-3241.

[238] W.-T. Koo, J.-S. Jang, I.-D. Kim, Chem 2019, 5, 1938-1963.

[239] A. Ejsmont, J. Andreo, A. Lanza, A. Galarda, L. Macreadie, S. Wuttke, S. Canossa, E. Ploetz, S. Wuttke, S. Canossa, E. Ploetz, J. Goscianska, Coord. Chem. Rev. 2020, 213655

[240] L. S. Xie, G. Skorupskii, M. Dincă, Chem. Rev. 2020, 120, 85368580.

[241] D. W. Lim, H. Kitagawa, Chem. Rev. 2020, 120, 8416-8467.

[242] R. Zhao, Y. Wu, Z. Liang, L. Gao, W. Xia, Y. Zhao, R. Zou, Energy Environ. Sci. 2020, 13, 2386-2403.

[243] A. A. Talin, A. Centrone, A. C. Ford, M. E. Foster, V. Stavila, P. Haney, R. A. Kinney, V. Szalai, F. El Gabaly, H. P. Yoon, F. Léonard, M. D. Allendorf, Science 2014, 343, 66-69.

[244] D. Sheberla, L. Sun, M. A. Blood-forsythe, S. Er, C. R. Wade, C. K. Brozek, A. Aspuru-Guzik, M. Dincă, J. Am. Chem. Soc. 2014, 136, 8859-8862.

[245] M. L. Aubrey, R. Ameloot, B. M. Wiers, J. R. Long, Energy Environ. Sci. 2014, 7, 667
[246] L. S. Xie, L. Sun, R. Wan, S. S. Park, J. A. DeGayner, C. H Hendon, M. Dincă, J. Am. Chem. Soc. 2018, 140, 7411-7414.

[247] W. Xu, X. Pei, C. S. Diercks, H. Lyu, Z. Ji, O. M. Yaghi, J. Am. Chem. Soc. 2019, 141, 17522-17526.

[248] C. R. Groom, I. J. Bruno, M. P. Lightfoot, S. C. Ward, IUCr, Acta Crystallogr. Sect. B Struct. Sci. Cryst. Eng. Mater. 2016, 72, 171179

[249] R. W. Day, D. K. Bediako, M. Rezaee, L. R. Parent, G. Skorupskii, M. Q. Arguilla, C. H. Hendon, I. Stassen, N. C. Gianneschi, P. Kim, M. Dincă, ACS Cent. Sci. 2019, 5, 1959-1964.

[250] M. Eddaoudi, J. Kim, N. Rosi, D. Vodak, J. Wachter, M. O'Keeffe, O M. Yaghi, Science 2002, 295, 469-472.

[251] L. S. Xie, G. Skorupskii, M. Dincă, Chem. Rev. 2020, 120, 85368580 .

[252] L. Sun, M. G. Campbell, M. Dincə, Angew. Chemie - Int. Ed. 2016, 55, 3566-3579.

[253] P. I. Scheurle, A. Mähringer, A. C. Jakowetz, P. Hosseini, A. F. Richter, G. Wittstock, D. D. Medina, T. Bein, Nanoscale 2019, 11, 20949-20955

[254] K. Ye, D. L. Kaplan, G. Bao, C. Bettinger, G. Forgacs, C. Dong, A. Khademhosseini, Y. Ke, K. Leong, A. Sambanis, W. Sun, P. Yin, ACS Biomater. Sci. Eng. 2018, 4, 2292-2307.

[255] S. Goswami, D. Ray, K. Otake, C.-W. Kung, S. J. Garibay, T. Islamoglu, A. Atilgan, Y. Cui, C. J. Cramer, O. K. Farha, J. T. Hupp, Chem. Sci. 2018, 9, 4477-4482.

[256] B. Dhara, S. S. Nagarkar, J. Kumar, V. Kumar, P. K. Jha, S. K. Ghosh, S. Nair, N. Ballav, J. Phys. Chem. Lett. 2016, 7, 2945-2950.

[257] Y.-Q. Hu, M.-Q. Li, Y. Wang, T. Zhang, P.-Q. Liao, Z. Zheng, X.-M. Chen, Y.-Z. Zheng, Chem. - A Eur. J. 2017, 23, 8409-8413.

[258] L. Sun, C. H. Hendon, M. A. Minier, A. Walsh, M. Dincă, J. Am. Chem. Soc. 2015, 137, 6164-7.

[259] M. Bendikov, F. Wudl, D. F. Perepichka, Chem. Rev. 2004, 104 4891-4945.

[260] J. G. Park, M. L. Aubrey, J. Oktawiec, K. Chakarawet, L. E. Darago, F. Grandjean, G. J. Long, J. R. Long, J. Am. Chem. Soc. 2018, 140, 8526-8534.

[261] L. Liu, J. A. DeGayner, L. Sun, D. Z. Zee, T. D. Harris, Chem. Sci. 2019, 10, 4652-4661.

[262] Z. Zhang, Y. Shao, B. Lotsch, Y. S. Hu, H. Li, J. Janek, L. F. Nazar, C. W. Nan, J. Maier, M. Armand, L. Chen, Energy Environ. Sci. 2018, 11, 1945-1976.

[263] Yung-Fang Yu Yao, J. T. Kummer, J. Inorg. Nucl. Chem. 1967, 29, 2453-2475.

[264] E. M. Miner, S. S. Park, M. Dinca, J. Am. Chem. Soc. 2019, 141, 4422-4427.

[265] H. Phan, T. S. Herng, D. Wang, X. Li, W. Zeng, J. Ding, K. P. Loh A. T. Shen Wee, J. Wu, Chem 2019, 5, 1223-1234.

[266] K. Fujie, R. Ikeda, K. Otsubo, T. Yamada, H. Kitagawa, Chem. Mater. 2015, 27, 7355-7361.

[267] Z. Wang, R. Tan, H. Wang, L. Yang, J. Hu, H. Chen, F. Pan, Adv. Mater. 2018, 30, 1704436.

[268] J. Wu, X. Guo, Small 2019, 15, 1804413.

[269] B. M. Wiers, M. L. Foo, N. P. Balsara, J. R. Long, J. Am. Chem. Soc. 2011, 133, 14522-14525. 


\section{Table of Contents}

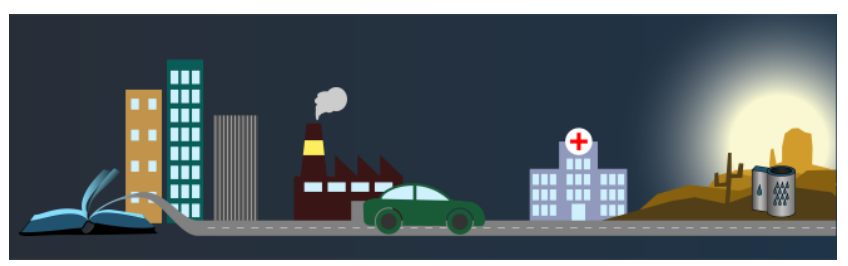

Institute and/or researcher Twitter usernames:

@wuttkescience, @BCMaterials, @ goscianskagroup, @UAM_Poznan, @ aejsmont, @bvkna, @jorgascon, @DincaGroupMIT, @AmelootGroup, @KU_Leuven 